\title{
Metal Particle Size and Structure of the Metal-Support Interface of Carbon-Supported Platinum Catalysts as Determined with EXAFS Spectroscopy
}

\author{
Yihua Zhang, ${ }^{\dagger}$ Marjolein L. Toebes, ${ }^{\dagger}$ Ad van der Eerden, ${ }^{\dagger}$ William E. O’Grady, \\ Krijn P. de Jong, ${ }^{\dagger}$ and Diek C. Koningsberger*, ${ }^{\dagger}$ \\ Department of Inorganic Chemistry and Catalysis, Debye Institute, Utrecht University, Sorbonnelaan 16, \\ 3584 CA, Utrecht, The Netherlands and Chemistry Division, Naval Research Laboratory, \\ Washington, D.C. 20375
}

Received: January 8, 2004; In Final Form: July 12, 2004

\begin{abstract}
The metal particle size and structure of the metal-support interface of platinum supported on Vulcan XC-72 (a commercial catalyst used in platinum fuel-cell electrodes) and on carbon nanofibers (CNF) have been determined with extended X-ray absorption fine structure spectroscopy (EXAFS). The CNF-supported Pt catalysts were synthesized using a homogeneous deposition precipitation (HDP) method. The amount of acidic oxygen groups on the CNF surface was modified by treatment in an inert atmosphere at different temperatures. The average first shell $\mathrm{Pt}-\mathrm{Pt}$ coordination number $(\sim 5.5)$ detected in $\mathrm{Pt} / \mathrm{CNF}$ is much smaller than for $\mathrm{Pt} /$ Vulcan XC-72 ( 8.2). The presence of oxygen-containing groups in the CNF support most probably leads to the stabilization of small Pt particles on the CNF support. A prominent interaction between the metal particles and the support atoms was detected on both kinds of catalysts, which confirms that the metal is in direct contact with the carbon support atoms. After reduction, a long metal-carbon distance around $2.62 \AA$ was detected in both Pt/Vulcan XC-72 and Pt/CNF. After evacuation of Pt/CNF at higher temperatures, the distance between support and interfacial metal atoms decreased to $2.02 \AA$. Therefore, the long metal-carbon support distance is ascribed to the presence of atomic chemisorbed hydrogen in the interface between the Pt particles and the carbon support. According to the number of interfacial $\mathrm{Pt}-\mathrm{C}$ bonds (four), the platinum particles supported on $\mathrm{CNF}$ are proposed to be in contact with a prismatic surface of the carbon support, on which oxygen groups have more stable bonds with carbon atoms. Six $\mathrm{Pt}-\mathrm{C}$ bonds could be detected in the metal-support interface of Pt/Vulcan XC-72 with an even longer carbon shell at $3.62 \AA$, indicating that the metal particles are located on a more carbon-rich surface. This supports a structural model in which the platinum metal particles are epitaxially grown on the (0001) basal surface plane of carbon graphite.
\end{abstract}

\section{Introduction}

Carbon as a support for small metal particles has been used for many decades in electrochemistry. There is gaining interest in $\mathrm{Pt} / \mathrm{C}$ electrochemistry ${ }^{1-3}$ and catalysis. ${ }^{4-11}$ It has been shown that precious metals supported on carbon nanofibers, which can be optimized by modification of the surface groups, provide highly active and selective catalysts in hydrogenation reactions. ${ }^{12,13}$ It has been well established that the physicochemical properties of the carbon support can have a dramatic effect on the catalytic properties of the supported metal. ${ }^{14,15}$ The work of Yacaman ${ }^{16}$ has shown that there is a strong interaction between small Pt particles and a graphite surface. Furthermore, it has been demonstrated that similar interactions occur when high-surface-area platinum is supported on carbon black. ${ }^{17}$ Recent XAFS studies ${ }^{18,19}$ have revealed more structural details about Pt fuel-cell electrodes. However, the structure of the metal-support interface for carbon-supported Pt particles is not as well studied as for metal particles supported on conventional oxidic or zeolite supports. Whereas the influence of oxidic (macroporous and crystalline zeolitic) supports on the catalytic and electronic properties of the supported metal particles has

* To whom correspondence should be addressed. Phone: +31-302536766. Fax: +31-30-2511027. E-mail: d.c.koningsberger@chem.uu.nl.

† Debye Institute

$\doteqdot$ Naval Research Laboratory. been extensively studied, ${ }^{20-22}$ a fundamental understanding of the nature of the interactions between the carbon support and the dispersed metal is lacking. Therefore, it would be of great importance to gain knowledge on the structure of the metalsupport interface in order to further understand the metalsupport interactions in carbon-supported metal catalysts.

EXAFS has been proven to be a unique tool for studying the structure of the metal particles and metal-support interface in highly dispersed supported metal catalysts. Detailed structural information has been obtained for $\mathrm{Rh} / \mathrm{Al}_{2} \mathrm{O}_{3}, \mathrm{Rh} / \mathrm{TiO}_{2}, \mathrm{Ir} / \mathrm{MgO}$, $\mathrm{Ir} / \mathrm{Al}_{2} \mathrm{O}_{3}, \mathrm{Pt} / \mathrm{Al}_{2} \mathrm{O}_{3}, \mathrm{Pt} / \mathrm{LTL}$, and Pt/Y zeolite. ${ }^{20,23-29}$ The EXAFS results show metal-oxygen interactions characterized by both short $(\sim 2.10-2.20 \AA)$ and long $(\sim 2.5-2.8 \AA)$ distances. ${ }^{26}$ By combining the results of temperature-programmed desorption (TPD) and XAFS experiments, Vaarkamp et al. ${ }^{27}$ proposed that the long metal-oxygen distance is due to the presence of hydrogen in the metal-support interface, because evacuation leads to a shortening of this distance. Further proof for this proposal was obtained from the XAFS experiments carried out on $\mathrm{Ir} / \mathrm{Al}_{2} \mathrm{O}_{3}$ catalysts. ${ }^{26}$ The long metal-oxygen distance was shown to be reversible: Admission of hydrogen after the evacuation treatment restored the originally observed long metal-oxygen distance. Furthermore, the authors found that, when the reduction temperature is raised from 300 to $450{ }^{\circ} \mathrm{C}$, the long metal-oxygen distance irreversibly disappeared; only 
TABLE 1: Carbon-Supported Platinum Catalysts

\begin{tabular}{|c|c|c|c|c|}
\hline \multirow[b]{2}{*}{ sample name } & \multirow{2}{*}{$\begin{array}{l}\text { Pt loading } \\
\text { (wt } \% \text { ) }\end{array}$} & \multirow{2}{*}{$\begin{array}{l}\text { TEM } \\
(\mathrm{nm})\end{array}$} & \multicolumn{2}{|c|}{ hydrogen chemisorption } \\
\hline & & & $H_{\text {total }} / \mathrm{Pt}$ & $H_{\text {irr }} / \mathrm{Pt}$ \\
\hline Pt/Vulcan XC-72 & 10 & 2.0 & & \\
\hline $\mathrm{Pt} / \mathrm{CNF} 200$ & 3.4 & 1.4 & 0.79 & 0.37 \\
\hline $\mathrm{Pt} / \mathrm{CNF} 500$ & 3.4 & 1.5 & 0.74 & 0.33 \\
\hline
\end{tabular}

a short metal-oxygen distance was observed in the presence of hydrogen. These results led to the idea that the presence of surface hydroxyl groups is a prerequisite for the movement of hydrogen between the metal particle and the support, thereby leading to the long metal-oxygen interfacial distance. However, a detailed understanding of the related mechanism is still lacking.

In this paper, the particle size and the structure of the metalsupport interface of two different $\mathrm{Pt} / \mathrm{C}$ catalysts has been determined with EXAFS. First, a CNF-supported Pt catalyst with different amounts of oxygen groups on the carbon surface was investigated. The oxygen-containing groups have a strong influence on the hydrogenation properties of this $\mathrm{Pt} / \mathrm{CNF}$ catalyst. ${ }^{30,31}$ The Pt particles were surprisingly stable, and TEM showed Pt particles with sizes in the range $1.2-1.4 \mathrm{~nm}$. As a comparison, a commercial Pt/Vulcan XC-72 catalyst used in fuel cell applications with metal particle sizes in the range 1.8$2.0 \mathrm{~nm}$ was also studied. The changes in the metal particle and metal-support interface structure induced by adsorption of hydrogen have been discussed. The results of our XAFS study on the $\mathrm{Pt} / \mathrm{CNF}$ catalysts show clear evidence for an interfacial platinum-carbon distance of around $2.65 \AA$ due to the presence of hydrogen in the platinum-carbon interface. The interfacial Pt atoms of the CNF-supported Pt particles are proposed to be in contact with a prismatic surface of the support, on which oxygen groups have more stable bonds with carbon atoms. However, the platinum atoms in the interface of $\mathrm{Pt} / \mathrm{Vulcan} \mathrm{XC}$ 72 sample have a (111) orientation in contact with a (0001) basal surface plane of the carbon.

\section{Experimental Section}

2.1. Synthesis of Carbon-Supported Platinum Catalysts. $\mathrm{Pt} /$ Vulcan XC-72 is a commercial catalyst used in fuel cell applications. The sample contains $10 \mathrm{wt} \% \mathrm{Pt}$ on Vulcan XC72.

The synthesis of CNF has been reported elsewhere. ${ }^{32}$ Platinum (3.4 wt \%) was deposited on the fibers using an HDP method. To an acidified suspension $(\mathrm{pH}=3)$ of $5 \mathrm{~g} \mathrm{CNF}$ in $250 \mathrm{~mL}$ demiwater heated to $90{ }^{\circ} \mathrm{C}, 0.41 \mathrm{~g}$ of urea (Acros) and $0.52 \mathrm{~g}$ of $\mathrm{Pt}\left(\mathrm{NH}_{3}\right)_{4}\left(\mathrm{NO}_{3}\right)_{2}$ were added under vigorous stirring. The $\mathrm{pH}$ of the slurry was monitored continuously. After $18 \mathrm{~h}$, the loaded $\mathrm{CNF}$ were filtered and washed thoroughly with demineralized water (conductivity), dried at $120^{\circ} \mathrm{C}$, and reduced with $\mathrm{H}_{2}$ at $200{ }^{\circ} \mathrm{C}$ for $1 \mathrm{~h}$ (heating rate $=5{ }^{\circ} \mathrm{C} / \mathrm{min}$ ).

The freshly reduced catalysts contained oxygen-containing groups with $\mathrm{O} / \mathrm{C}$ atomic ratio of 0.038 in the $\mathrm{CNF}$ support as determined by XPS, ${ }^{33}$ further indicated by Pt/CNF200. To change the concentration of oxygen-containing groups on the CNF surface, samples of the freshly reduced catalyst were heattreated in a nitrogen atmosphere for $2 \mathrm{~h}$ to vary the amount of oxygen-containing groups. In this study also, a catalyst treated at $500{ }^{\circ} \mathrm{C}$ was investigated $\left(\mathrm{O} / \mathrm{C}\right.$ atomic ratio of $0.026,{ }^{33}$ further indicated as Pt/CNF500). The catalyst samples together with their identification codes are listed in Table 1.

2.2. Catalyst Characterization. The average diameter of the platinum particles in $\mathrm{Pt} /$ Vulcan XC-72 was $1.8-2.0 \mathrm{~nm}$ as determined by electron microscopy. The CNF-supported platinum catalysts were examined in a Philips Technic 20 FEG TEM operated at $200 \mathrm{kV}$. Samples were prepared by suspending the fibers in ethanol under ultrasonic vibration. Some drops of the thus-produced suspension were brought onto a holey carbon film on a copper grid.

Hydrogen chemisorption measurements were performed using a Micromeritics ASAP 2010C. Before the chemisorption measurements, each sample was dried in $\mathrm{He}$ at $120{ }^{\circ} \mathrm{C}$ for $1 \mathrm{~h}$ and reduced in flowing $\mathrm{H}_{2}$ (flow rate $=50 \mathrm{~mL} / \mathrm{min} \mathrm{STP}$ ) at $200{ }^{\circ} \mathrm{C}$ for $2 \mathrm{~h}$, heating rate $5{ }^{\circ} \mathrm{C} / \mathrm{min}$. After reduction, the catalyst was degassed for $2 \mathrm{~h}$ at $10^{-1} \mathrm{~Pa}$ at the reduction temperature in order to eliminate chemisorbed hydrogen and water. The first (total amount of chemisorbed hydrogen) and second (amount of reversible chemisorbed hydrogen) isotherms were measured at $35{ }^{\circ} \mathrm{C}$. The $\mathrm{H} / \mathrm{Pt}$ ratios are based on the adsorbed amounts at zero pressure found by extrapolation of the linear part of the isotherm.

2.3. XAFS Spectroscopy. XAFS Data Collection. The X-ray absorption data at the $\mathrm{Pt}_{3}$ edge of the Pt/Vulcan XC-72 sample were measured in the transmission mode on beam line X11-A of the National Synchrotron Light Source (NSLS), Brookhaven National Laboratory, U.S.A. The station was operated with a double crystal monochromator, $\operatorname{Si}(111)$, detuned to $20 \%$ intensity to minimize the presence of higher harmonics. The X-ray absorption spectra (both $\mathrm{Pt}_{3^{-}}$and $\mathrm{L}_{2}$-edge) of the $\mathrm{Pt} / \mathrm{CNF}$ samples were collected at HASYLAB synchrotron (Beamline X1.1) in Hamburg, Germany. The monochromator was detuned to $50 \%$ of maximum intensity to avoid higher harmonics present in the X-ray beam. All measurements were done in transmission using ion chambers filled with a mixture of $\mathrm{Ar}$ and $\mathrm{N}_{2}$ to have an X-ray absorbance of $20 \%$ in the first and $80 \%$ in the second chamber.

The samples were pressed into self-supporting wafers (calculated to have an absorbency of 2.5) and mounted in a controlled-atmosphere cell operated at 1 atm. $^{34}$ All EXAFS experiments were carried out at liquid nitrogen temperatures.

The Pt/Vulcan XC-72 sample was treated in flowing hydrogen at room temperature (RT) (indicated by REDRT), and the EXAFS spectra were collected under $1 \mathrm{~atm}$ of hydrogen. The sample was further evacuated for $1 \mathrm{~h}$ at RT (indicated by VACRT) followed by EXAFS measurements maintaining a vacuum better than $10^{-3} \mathrm{~Pa}$.

The Pt/CNF samples were in situ reduced at $200{ }^{\circ} \mathrm{C}$ for $1 \mathrm{~h}$ in flowing hydrogen and cooled in hydrogen (treatment denoted as RED), and the EXAFS data were measured under 1 atm of hydrogen. Subsequently, the samples were evacuated at 50, 100, 150 , and $200{ }^{\circ} \mathrm{C}$ for $30 \mathrm{~min}$ (treatments denoted as VAC50, VAC100, VAC150, and VAC200, respectively). After each evacuation, the EXAFS data were collected maintaining a vacuum better than the $10^{-3} \mathrm{~Pa}$ sample.

The Pt $\mathrm{L}_{3}$-edge of Pt foil and $\left[\mathrm{Rb}_{2} \mathrm{Pt}(\mathrm{CN})_{4}\right] \cdot\left(1.5 \mathrm{H}_{2} \mathrm{O}\right)$ were also measured and used to obtain phase shifts and backscattering amplitudes of the $\mathrm{Pt}-\mathrm{Pt}$ and $\mathrm{Pt}-\mathrm{C}$ absorber-backscatterer pairs, respectively.

EXAFS Data Analysis. Extraction of the EXAFS data from the measured absorption spectra was performed with the XDAP code. ${ }^{35}$ Three scans were averaged, and the pre-edge was subtracted using a modified Victoreen curve. The background was subtracted employing cubic spline routines with a continuously adjustable smooth parameter. Normalization was performed by dividing the data by the height of the absorption edge at $50 \mathrm{eV}$.

Data analysis was performed by multiple shell fitting in $R$-space using the EXAFS data-analysis program XDAP, which allows one to minimize the residuals between both the magni- 
TABLE 2:

(a) Parameters Used in the Calculations for the Generation of Theoretical Refs

\begin{tabular}{llcccc}
\hline atom pair & \multicolumn{1}{c}{ potential } & $\sigma^{2}\left[\AA^{2}\right]$ & $S_{0}^{2}$ & $V_{\mathrm{r}}[\mathrm{eV}]$ & $V_{\mathrm{i}}[\mathrm{eV}]$ \\
\hline $\mathrm{Pt}-\mathrm{Pt}$ & Dirac-Hara & 0.00234 & 0.82 & -4.2 & 3.0 \\
$\mathrm{Pt}-\mathrm{C}$ & Hedin-Linquist & 0.00200 & 0.93 & -10.4 & 3.0
\end{tabular}

(b) Best Fit Result for the Exptl Pt Foil and $\mathrm{Rb}_{2} \mathrm{Pt}(\mathrm{CN})_{4} \cdot\left(1.5 \mathrm{H}_{2} \mathrm{O}\right)$ Data Using the Theoretical Refs ${ }^{a}$

\begin{tabular}{lllrc}
\hline \multicolumn{1}{c}{ atom pair } & $N$ & $R(\AA)$ & $\Delta \sigma\left(\AA^{2}\right)$ & $E_{0}(\mathrm{eV})$ \\
\hline $\mathrm{Pt}-\mathrm{Pt}$ & 11.7 & 2.77 & -0.00004 & 0.08 \\
$\mathrm{Pt}-\mathrm{C}$ & 3.9 & 1.98 & 0.00001 & 0.02
\end{tabular}

${ }^{a}$ Fits were performed in $R$-space, $k^{3}$-weighted. Pt-foil: $\Delta k=2.5-$ $15 \AA^{-1} ; \Delta R=1.5-3.2 \AA . \mathrm{Rb}_{2} \mathrm{Pt}(\mathrm{CN})_{4} \cdot\left(1.5 \mathrm{H}_{2} \mathrm{O}\right): \Delta k=2.5-12.9$ $\AA^{-1} ; \Delta R=1.0-2.0 \AA$.

tude and the imaginary part of the Fourier transforms of the data and the fit. $R$-space fitting has significant advantages compared to the usually applied fitting in $k$-space and is extensively discussed in a recent paper by Koningsberger et al. ${ }^{36}$ The difference file technique was applied together with phase- and amplitude-corrected Fourier transforms to resolve the different contributions in the EXAFS data. The difference file technique allows one to optimize each individual contribution with respect to the other contributions present in the EXAFS spectrum. ${ }^{36}$ Both high $Z(\mathrm{Pt}-\mathrm{Pt})$ and low $Z(\mathrm{Pt}-\mathrm{C})$ contributions are present in the EXAFS data collected on carbon-supported platinum. A $k^{3}$ weighting emphasizes the high $Z$ contributions to the spectrum, while $k^{1}$ weighting focuses on the low $Z$. In this study, the EXAFS fits have been checked by applying $k^{1}$ and $k^{3}$ weightings in order to be certain that the results are the same for all weightings. ${ }^{37}$

Theoretical phase shifts and backscattering amplitudes for the $\mathrm{Pt}-\mathrm{Pt}$ and $\mathrm{Pt}-\mathrm{C}$ absorber-scattering pairs were used in EXAFS data analysis, which were generated utilizing the FEFF7 code with the parameters listed in Table 2a. The theoretical references were calibrated with the help of the experimental data of $\mathrm{Pt}$ foil and $\left[\mathrm{Rb}_{2} \mathrm{Pt}(\mathrm{CN})_{4}\right] \cdot\left(1.5 \mathrm{H}_{2} \mathrm{O}\right)$ employing the procedure reported in ref 36 . Table $2 \mathrm{~b}$ gives the best fit result for the experimental $\mathrm{Pt}$ foil and $\mathrm{Rb}_{2} \mathrm{Pt}(\mathrm{CN})_{4} \cdot\left(1.5 \mathrm{H}_{2} \mathrm{O}\right)$ data using the theoretical references. The fitted EXAFS coordination parameters correspond with the crystallographic values for $\mathrm{Pt}$ foil $(N=12$ and $R=2.77 \AA)$ and for $\operatorname{Rb}_{2} \mathrm{Pt}(\mathrm{CN})_{4} \cdot\left(1.5 \mathrm{H}_{2} \mathrm{O}\right)(N$ $=4$ and $R=1.99 \AA$ ).

\section{Results}

3.1. Pt/CNF. TEM and Hydrogen Chemisorption. The physicochemical properties of carbon nanofibers employed in this paper have been reported elsewhere. ${ }^{32}$ The CNF were of the fishbone type, and an average fiber diameter of $25 \mathrm{~nm}$ was derived from SEM results. The XPS results show that $\mathrm{O} / \mathrm{C}$ atomic ratios of 0.038 and 0.026 were determined in the freshly reduced catalyst $(\mathrm{Pt} / \mathrm{CNF} 200)$ and the catalyst treated in inert atmosphere at $500{ }^{\circ} \mathrm{C}(\mathrm{Pt} / \mathrm{CNF} 500)$, respectively. The metal loading of the CNF-supported platinum catalysts as determined with inductively couple plasma (ICP) analysis amounts to 3.4 wt \%. In Figure 1a,b, two TEM images of Pt/CNF200 and Pt/ CNF500 are shown. The platinum particles appear as dark dots with a very narrow size distribution on the surface of the CNF. Average particle sizes of 1.4 and $1.5 \mathrm{~nm}$ were obtained from the TEM images for Pt/CNF200 and Pt/CNF500, respectively, as concluded in Table 1 . Pt/CNF500 presents a similar size distribution to $\mathrm{Pt} / \mathrm{CNF} 200$ without any treatment in inert atmosphere. This implies that platinum nanoparticles supported
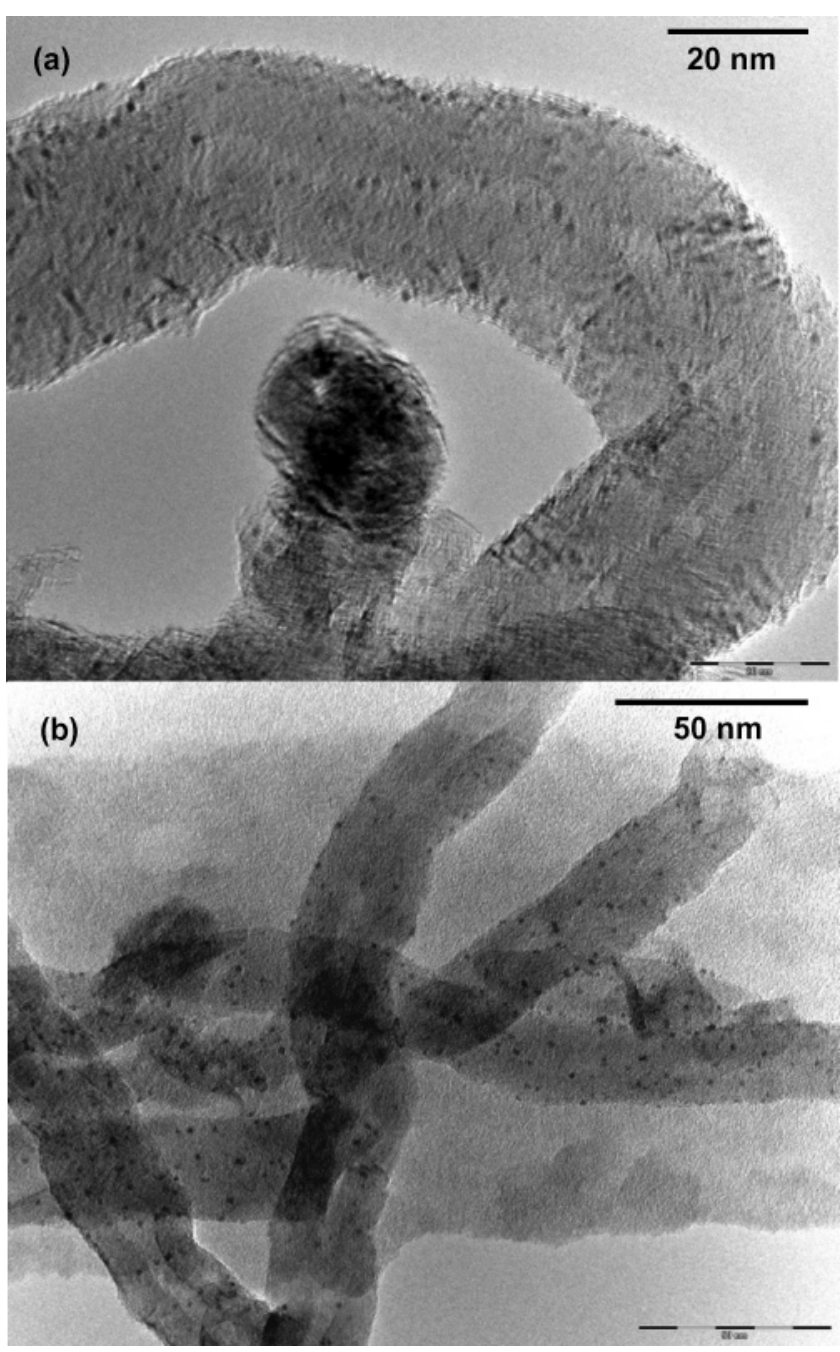

Figure 1. TEM images of (part a) Pt/CNF200 and (part b) Pt/CNF500.

on CNF in this study are very thermally stable. Hydrogen chemisorption shows a small decrease in $H_{\text {total }} / \mathrm{Pt}$ from 0.79 on $\mathrm{Pt} / \mathrm{CNF} 200$ to 0.74 on Pt/CNF500.

EXAFS Data Analysis. The experimental EXAFS data $\left(k^{1}\right.$ weighted, $\Delta k=2-14 \AA^{-1}$ ) of Pt/CNF200 and Pt/CNF500 are plotted in Figure $2 \mathrm{a}$ and $\mathrm{b}$, respectively. The signal-to-noise ratio at $k=4.4 \AA^{-1}$ amounts to approximately 150 for both $\mathrm{Pt} / \mathrm{CNF} 200$ and Pt/CNF500, showing the excellent data quality. The amplitude of oscillations decreased with the nodes shifted to higher $k$ values upon increasing the evacuation temperature. These spectral changes are due to variations in both the structure of the metal particle and the metal-support interface induced by the desorption of chemisorbed hydrogen. It can clearly be seen that the temperature dependence of the changes induced by the desorption of hydrogen is different for both samples.

Figure $3 \mathrm{a}, \mathrm{b}$ display the corresponding Fourier transforms $\left(k^{1}\right.$ weighted, $\Delta k=3-14 \AA^{-1}$ ) of the EXAFS data of Pt/CNF200 and Pt/CNF500 for the different treatments (RED, VAC100, and VAC200). Figure 3 shows that, with increasing evacuation temperature, the spectra (both the magnitude and the imaginary part of the Fourier transform) shift to lower values of $R$. The amplitude of the contributions at $R<2 \AA$, which includes AXAFS and $\mathrm{Pt}-\mathrm{C}(\mathrm{O})$ contributions, is enhanced with the trend in the opposite direction for the range $\sim 2-3 \AA$. Also, the Fourier transforms show clearly that the temperature dependence of the changes induced by desorption of hydrogen is different for both samples. 

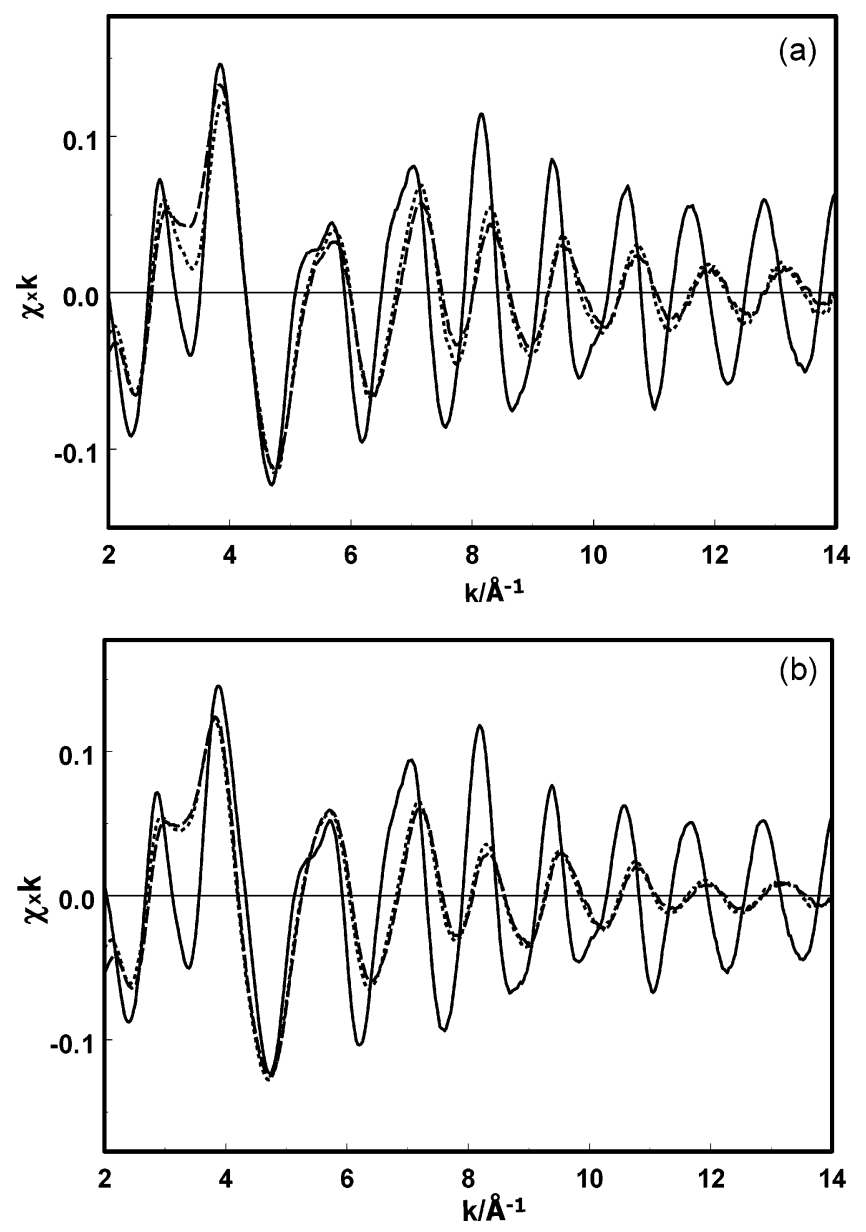

Figure 2. The experimental EXAFS data $\left(k^{1}\right.$ weighted, $\Delta k=2-14$ $\AA^{-1}$ ) of (part a) Pt/CNF200 and (part b) Pt/CNF500. Solid lines, RED; dotted lines, VAC100; and dashed line, VAC200.

Data analysis of the CNF-supported platinum catalysts was performed by multiple shell fitting in $R$ space in the range 1.6 $<R<3.2 \AA$. Pt and $\mathrm{C} / \mathrm{O}$ backscatterers were identified using the difference file technique. The EXAFS coordination parameters of Pt/CNF200 and Pt/CNF500 are given in Tables 3 and 4 , respectively. The $\mathrm{Pt}-\mathrm{Pt}$ first shell coordination numbers around 5.5 point to extremely small $\mathrm{Pt}$ particles with average particle sizes of about $1.1 \mathrm{~nm}$. Because it is very difficult to distinguish between $\mathrm{C}$ and $\mathrm{O}$ backscatterers, ${ }^{38}$ no attempt was made in this study to separate the $\mathrm{Pt}-\mathrm{C}$ and $\mathrm{Pt}-\mathrm{O}$ contributions. Figure 4 illustrates the comparison between the Fourier transform of the experimental EXAFS and best fit of Pt/CNF200. The results for Pt/CNF500 are of comparable quality.

The decrease in $\mathrm{Pt}-\mathrm{Pt}$ coordination distances and increase in Debye-Waller factors upon evacuation at increasing temperatures are displayed in Figure 5a,b. After desorption of hydrogen at low temperature $\left(50{ }^{\circ} \mathrm{C}\right)$, the first metal shell distance decreases with $0.06 \AA$ compared to the sample in an $\mathrm{H}_{2}$ atmosphere. After evacuation at 150 and $200{ }^{\circ} \mathrm{C}$, a further decrease of $0.01 \AA$ was observed. Meanwhile, the DebyeWaller factor increased from $1 \times 10^{-3}$ to $7 \times 10^{-3} \AA^{2}$.

Figure $6 \mathrm{a}, \mathrm{b}$ shows the Fourier transform of the difference file of the $\mathrm{Pt}-\mathrm{C}(\mathrm{O})$ contributions (raw data minus calculated $\mathrm{Pt}-\mathrm{Pt}$ contribution) and of the fit $\mathrm{Pt}-\mathrm{C}(\mathrm{O})$ for both $\mathrm{Pt} / \mathrm{CNF} 200$ and $\mathrm{Pt} / \mathrm{CNF} 500$. Removal of the dominant $\mathrm{Pt}-\mathrm{Pt}$ contributions makes the changes in the interfacial structure more clearly visible. The deviations between the Fourier transforms of the difference file and the Fourier transforms of the calculated model spectra at low values of $R$ are due to the presence of atomic
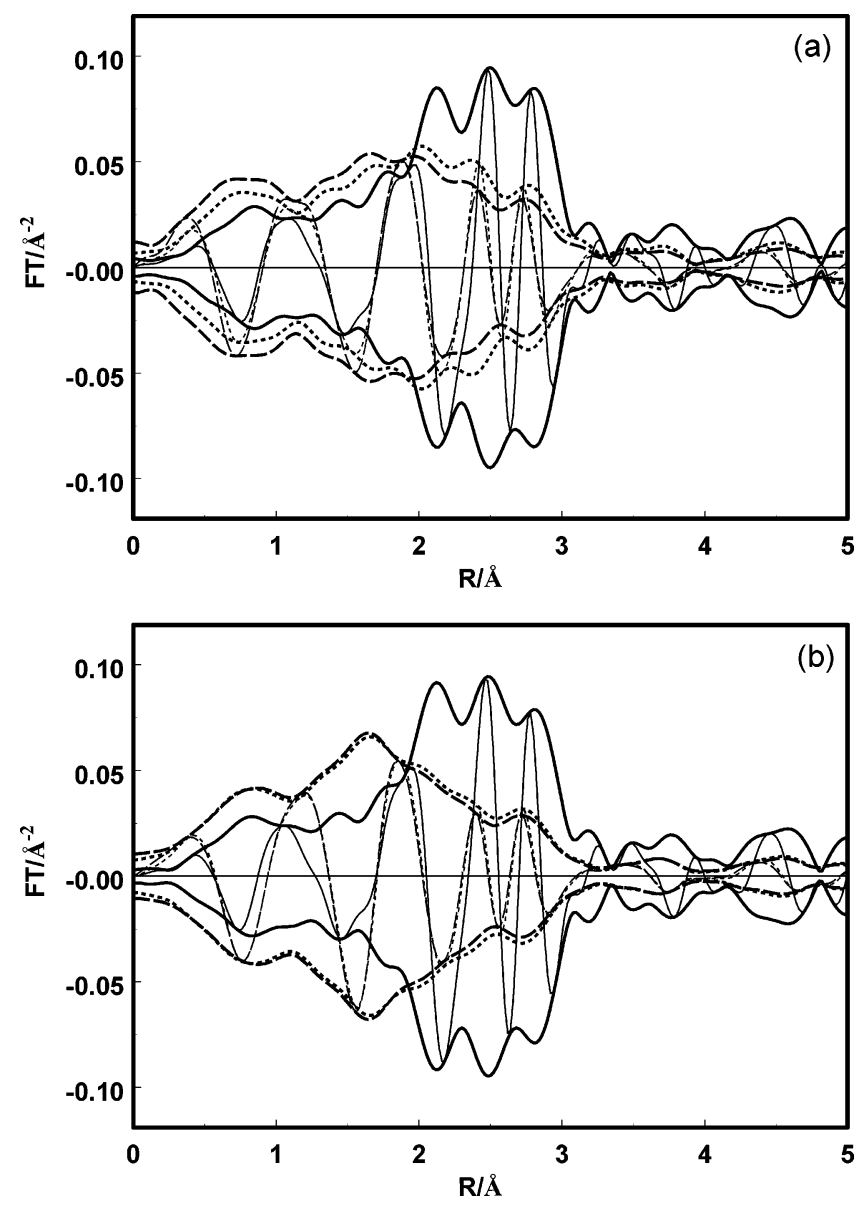

Figure 3. The Fourier transforms $\left(k^{1}\right.$ weighted, $\left.\Delta k=3-14 \AA^{-1}\right)$ of (part a) Pt/CNF200 and (part b) Pt/CNF500. Solid lines, RED; dotted lines, VAC100; and dashed line, VAC200.

TABLE 3: Fit Parameters of EXAFS Spectra ${ }^{a}$ and Variances for Model Spectra of Pt/CNF200

\begin{tabular}{|c|c|c|c|c|c|c|c|}
\hline \multirow[b]{2}{*}{ treatment } & \multirow[b]{2}{*}{ scatter } & \multirow{2}{*}{$\begin{array}{c}N \\
( \pm 10 \%)\end{array}$} & \multirow{2}{*}{$\begin{array}{c}R \\
(\AA \AA \\
\pm 0.02 \AA)\end{array}$} & \multirow{2}{*}{$\begin{array}{c}\Delta \sigma^{2} \\
\left(10^{-3} \AA^{2}\right. \\
\pm 5 \%)\end{array}$} & \multirow{2}{*}{$\begin{array}{c}\Delta E_{0} \\
(\mathrm{eV} \\
\pm 10 \%)\end{array}$} & \multicolumn{2}{|c|}{$\begin{array}{c}k^{1}-\text { variance } \\
(\%)\end{array}$} \\
\hline & & & & & & im. & abs. \\
\hline \multirow[t]{3}{*}{ RED } & $\mathrm{Pt}$ & 5.2 & 2.77 & 1.1 & 2.1 & 0.39 & 0.14 \\
\hline & $\mathrm{C}(\mathrm{O})_{\mathrm{L}}$ & 1.6 & 2.65 & 2.2 & -0.3 & & \\
\hline & $\mathrm{C}(\mathrm{O})_{\mathrm{S}}$ & 0.7 & 2.02 & 2.0 & 1.2 & & \\
\hline \multirow[t]{3}{*}{ VAC50 } & $\mathrm{Pt}$ & 5.6 & 2.71 & 3.9 & 3.0 & 0.10 & 0.04 \\
\hline & $\mathrm{C}(\mathrm{O})_{\mathrm{L}}$ & 0.9 & 2.59 & 4.1 & 2.6 & & \\
\hline & $\mathrm{C}(\mathrm{O})_{\mathrm{S}}$ & 1.1 & 2.01 & 3.8 & 5.3 & & \\
\hline \multirow[t]{3}{*}{ VAC100 } & $\mathrm{Pt}$ & 5.5 & 2.70 & 5.3 & 4.0 & 0.12 & 0.09 \\
\hline & $\mathrm{C}(\mathrm{O})_{\mathrm{L}}$ & 0.6 & 2.51 & 5.0 & 6.3 & & \\
\hline & $\mathrm{C}(\mathrm{O})_{\mathrm{S}}$ & 1.4 & 2.00 & 4.5 & 5.4 & & \\
\hline \multirow[t]{2}{*}{ VAC 150} & $\mathrm{Pt}$ & 5.6 & 2.70 & 5.5 & 3.4 & 0.28 & 0.15 \\
\hline & $\mathrm{C}(\mathrm{O})_{\mathrm{S}}$ & 1.5 & 2.02 & 6.6 & 1.9 & & \\
\hline \multirow[t]{2}{*}{ VAC200 } & $\mathrm{Pt}$ & 5.4 & 2.69 & 6.6 & 3.8 & 0.19 & 0.11 \\
\hline & $\mathrm{C}(\mathrm{O})_{\mathrm{S}}$ & 2.0 & 2.02 & 6.7 & 1.5 & & \\
\hline
\end{tabular}

XAFS. After reduction (RED) for both samples, a long distance $\mathrm{Pt}-\mathrm{C}(\mathrm{O})_{\mathrm{L}}$ (around $2.65 \AA$ ) was detected together with a very small contribution of a much shorter distance $\mathrm{Pt}-\mathrm{C}(\mathrm{O})_{\mathrm{S}}$ (around $2.02 \AA)$. When the evacuation temperature is increased, the contribution of the long distance decreases with a simultaneous increase of the contribution of the short distance. The disappearance of the long $\mathrm{Pt}-\mathrm{C}(\mathrm{O})_{\mathrm{L}}$ distance occurs at a lower evacuation temperature for the Pt/CNF500 than for the Pt/ CNF200 sample.

The long $\mathrm{Pt}-\mathrm{C}(\mathrm{O})_{\mathrm{L}}$ distance of approximately $2.60 \AA$ present after reduction is in accordance with previous reports on EXAFS studies over zeolite and/or alumina-supported metal particles 
TABLE 4: Fit Parameters of EXAFS Spectra ${ }^{a}$ and Variances for Model Spectra of Pt/CNF500

\begin{tabular}{|c|c|c|c|c|c|c|c|}
\hline \multirow[b]{2}{*}{ treatment } & \multirow[b]{2}{*}{ scatter } & \multirow{2}{*}{$\begin{array}{c}N \\
( \pm 10 \%)\end{array}$} & \multirow{2}{*}{$\begin{array}{c}R \\
(\AA \AA \\
\pm 0.02 \AA)\end{array}$} & \multirow{2}{*}{$\begin{array}{c}\Delta \sigma^{2} \\
\left(10^{-3} \AA^{2}\right. \\
\pm 5 \%)\end{array}$} & \multirow{2}{*}{$\begin{array}{c}\Delta E_{0} \\
(\mathrm{eV} \\
\pm 10 \%)\end{array}$} & \multicolumn{2}{|c|}{$\begin{array}{c}k^{1}-\text { variance } \\
(\%)\end{array}$} \\
\hline & & & & & & im. & abs. \\
\hline \multirow[t]{3}{*}{ RED } & $\mathrm{Pt}$ & 5.5 & 2.76 & 1.6 & 1.3 & 0.58 & 0.10 \\
\hline & $\mathrm{C}(\mathrm{O})_{\mathrm{L}}$ & 2.0 & 2.62 & 1.4 & 1.5 & & \\
\hline & $\mathrm{C}(\mathrm{O})_{\mathrm{S}}$ & 0.3 & 2.01 & 1.3 & 3.2 & & \\
\hline \multirow[t]{3}{*}{ VAC50 } & $\mathrm{Pt}$ & 5.4 & 2.70 & 5.7 & 3.5 & 0.34 & 0.12 \\
\hline & $\mathrm{C}(\mathrm{O})_{\mathrm{L}}$ & 0.7 & 2.55 & 2.3 & 5.3 & & \\
\hline & $\mathrm{C}(\mathrm{O})_{\mathrm{S}}$ & 1.6 & 2.02 & 1.8 & 3.8 & & \\
\hline \multirow[t]{2}{*}{ VAC100 } & $\mathrm{Pt}$ & 5.4 & 2.69 & 6.6 & 4.2 & 0.35 & 0.15 \\
\hline & $\mathrm{C}(\mathrm{O})_{\mathrm{s}}$ & 2.1 & 2.02 & 2.3 & 2.3 & & \\
\hline \multirow[t]{2}{*}{ VAC150 } & $\mathrm{Pt}$ & 5.3 & 2.68 & 7.0 & 3.7 & 0.21 & 0.08 \\
\hline & $\mathrm{C}(\mathrm{O})_{\mathrm{S}}$ & 2.2 & 2.02 & 2.7 & 1.6 & & \\
\hline \multirow[t]{2}{*}{ VAC200 } & $\mathrm{Pt}$ & 5.2 & 2.68 & 7.1 & 3.9 & 0.21 & 0.07 \\
\hline & $\mathrm{C}(\mathrm{O})_{\mathrm{S}}$ & 2.3 & 2.02 & 3.1 & 1.6 & & \\
\hline
\end{tabular}

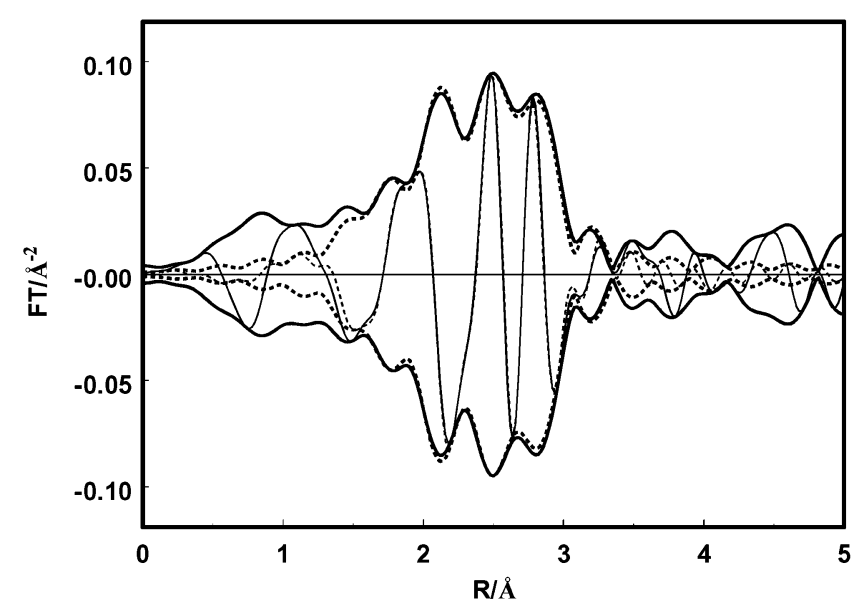

Figure 4. The Fourier transforms $\left(k^{1}\right.$ weighted, $\left.\Delta k=3-14 \AA^{-1}\right)$ of the experimental spectra (solid line) and total fit (dotted line) of $\mathrm{Pt} /$ CNF200 after reduction (RED).

and is due to the presence of interfacial hydrogen. ${ }^{27,28,39}$ It has to be noted that the total $\mathrm{Pt}-\mathrm{C}(\mathrm{O})$ coordination number stays constant around 2.0 in Pt/CNF200 and 2.3 in Pt/CNF500.

3.2. Pt/Vulcan XC-72. EXAFS Data Analysis. In Figure 7a,b, the raw EXAFS data and the corresponding Fourier transform spectra are displayed, characterizing the sample Pt/Vulcan XC72 after reduction at RT (REDRT) and after evacuation at RT (VACRT). The EXAFS data have an excellent quality (signalto-noise ratio of about 90 at $k=4 \AA^{-1}$ ). The differences for $2.5<R<3 \AA$ between the Fourier transforms of REDRT and VACRT (Figure 7b) are caused by the removal of chemisorbed hydrogen and are mostly due to an increase in the DebyeWaller factor of the first shell $\mathrm{Pt}-\mathrm{Pt}$ coordination of the VACRT sample.

The results of the EXAFS data analysis are given in Table 5. The $\mathrm{Pt}-\mathrm{Pt}$ coordination numbers around 8.2 points to metal particles of about $1.6 \mathrm{~nm}$, much larger than for the $\mathrm{Pt} / \mathrm{CNF}$ samples. After evacuation at RT, a larger Debye-Waller factor was obtained for the $\mathrm{Pt}-\mathrm{Pt}$ first shell contribution. Even for these larger $\mathrm{Pt}$ particles an interfacial $\mathrm{Pt}-\mathrm{C}$ coordination could be detected with a first and second $\mathrm{Pt}-\mathrm{C}$ shell distance of $\sim 2.6$ $\AA$ and $\sim 3.6 \AA$, respectively. The analysis of especially the second $\mathrm{Pt}-\mathrm{C}$ shell could only be reliably performed by including in the fit procedure the second $\mathrm{Pt}-\mathrm{Pt}$ shell, because this shell has a considerable overlap with the second $\mathrm{Pt}-\mathrm{C}$ shell. Figure 8 gives the Fourier transforms ( $k^{1}$ weighted, $\Delta k=3.5-14 \AA^{-1}$ ) of the experimental data of the REDRT sample and of the calculated total fit using the parameters listed in Table 5.
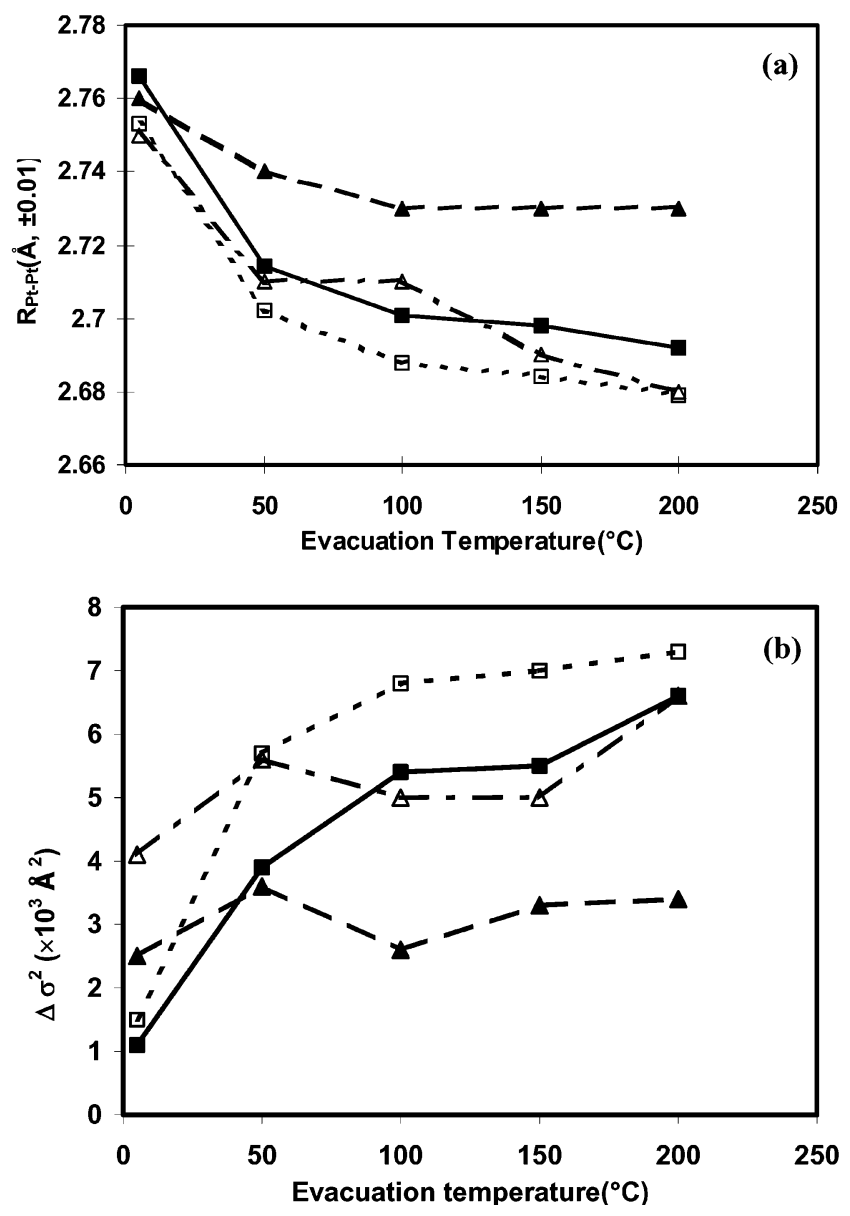

Figure 5. (part a) $\mathrm{Pt}-\mathrm{Pt}$ coordination distance and (part b) DebyeWaller factor as a function of sample treatment. Pt/CNF200, solid line with closed squares (ם), Pt/CNF500, dotted line with open squares ( $\square$ ). As comparison data of an acidic $\mathrm{Pt} / \mathrm{Cl}-\mathrm{Al}_{2} \mathrm{O}_{3}$, line with closed triangles $(\boldsymbol{\Delta})$; and basic $\mathrm{Pt} / \mathrm{K}-\mathrm{Al}_{2} \mathrm{O}_{3}$, dashed-dotted line with open triangles $(\triangle) .{ }^{46}$ The first points on the left refer to RED.

Comparable results are obtained for the fit of the EXAFS data after evacuation at RT (VACRT).

Figure 9a,b displays the Fourier transforms ( $k^{1}$ weighted, $\Delta k$ $=3.5-9.5 \AA^{-1}$ ) of the total $\mathrm{Pt}-\mathrm{C}$ difference file (raw EXAFS data minus fitted $\mathrm{Pt}-\mathrm{Pt}$ contributions $\left[\mathrm{Pt}-\mathrm{Pt}_{1}+\mathrm{Pt}-\mathrm{Pt}_{2}\right]$ and calculated model $\left(\mathrm{Pt}-\mathrm{C}_{1}\right)+\left(\mathrm{Pt}-\mathrm{C}_{2}\right)$ contributions. It can be clearly seen from the difference file that additional scatterers must be included. The coordination numbers for both shells are around 2.3 on REDRT and 2.6 on VACRT. However, hardly any difference in the structure of the interface between the $\mathrm{Pt}$ particles and the carbon support is observed after evacuation at RT.

\section{Discussion}

4.1. Pt Particle Size. The EXAFS first $\mathrm{Pt}-\mathrm{Pt}$ shell coordination number is about 5.5 in $\mathrm{Pt} / \mathrm{CNF}$ and 8.2 in Pt/Vulcan $\mathrm{XC}$ 72. By using a computer program ${ }^{40}$ to model spherical particles, it can be calculated that the EXAFS coordination numbers correspond to small $\mathrm{Pt}$ particles with sizes around $1 \mathrm{~nm}$ in $\mathrm{Pt} /$ $\mathrm{CNF}$ and $1.6 \mathrm{~nm}$ in Pt/Vulcan XC-72. Larger Pt metal particle sizes were determined by TEM of around $1.5 \mathrm{~nm}$ in $\mathrm{Pt} / \mathrm{CNF}$ and $2 \mathrm{~nm}$ in Pt/Vulcan XC-72, respectively. It has been demonstrated before that the determination of metal particle size using EXAFS coordination numbers is more accurate than the results from TEM if the average metal particle size is smaller than $2 \mathrm{~nm}$. This due to the fact that TEM may not detect the 

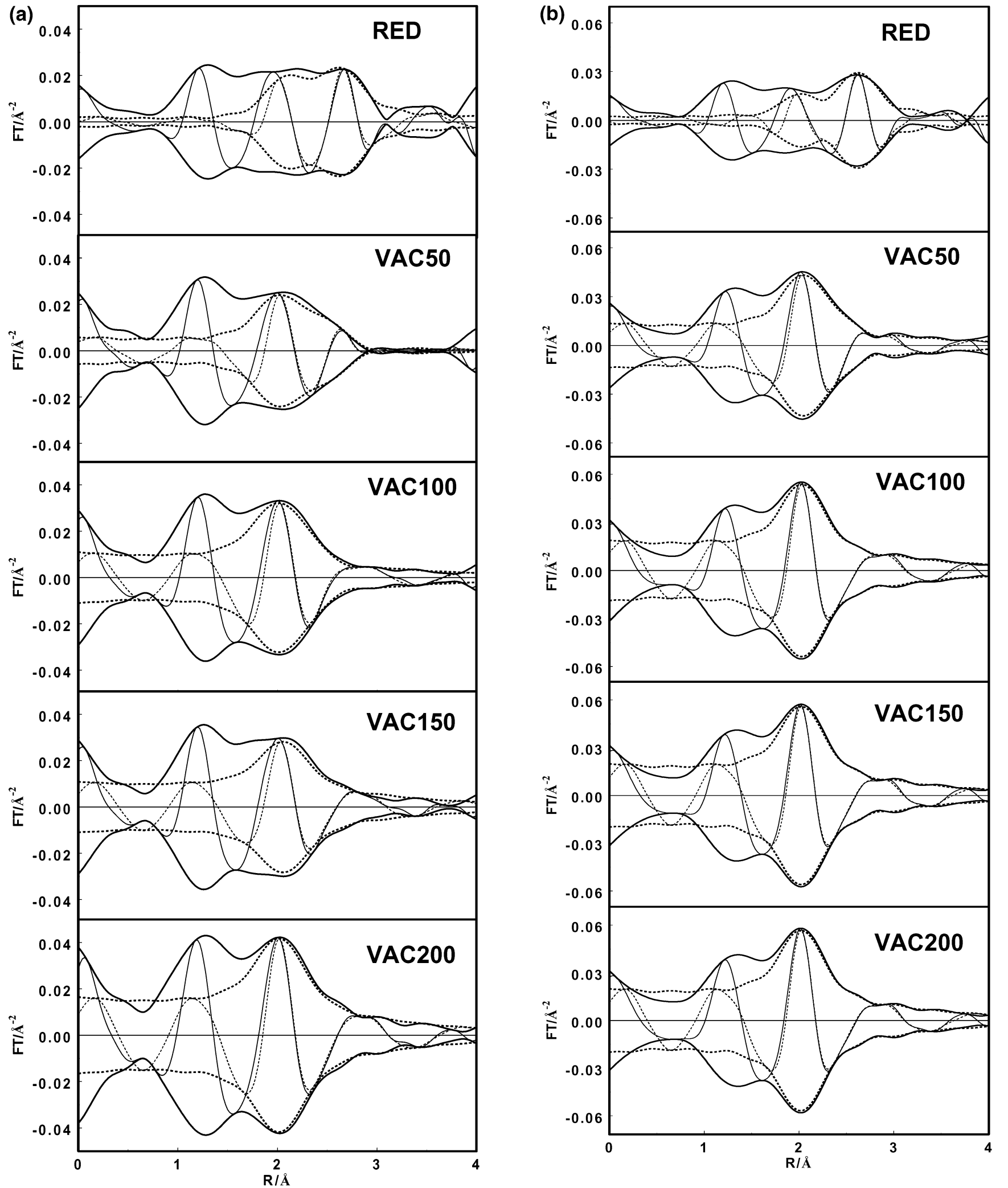

Figure 6. (part a) The Fourier transforms ( $k^{1}$ weighted, $\Delta k=3-11 \AA^{-1}, \mathrm{Pt}-\mathrm{C}$ phase-corrected) of the $\mathrm{Pt}-\mathrm{C}(\mathrm{O})$ difference file (raw spectra minus fitted $\mathrm{Pt}-\mathrm{Pt}$ contribution, solid line) and fitted $\mathrm{Pt}-\mathrm{C}(\mathrm{O})_{\mathrm{L}}+\mathrm{Pt}-\mathrm{C}(\mathrm{O})_{\mathrm{S}}$ contributions (dotted line) of $\mathrm{Pt} / \mathrm{CNF} 200$. Treatments are RED, VAC50, VAC100, VAC150, and VAC200, respectively. (part b) The Fourier transforms ( $k^{1}$ weighted, $\Delta k=3-11 \AA^{-1}, \mathrm{Pt}-\mathrm{C}$ phase-corrected) of the $\mathrm{Pt}-\mathrm{C}(\mathrm{O})$ difference file (raw spectra minus fitted $\mathrm{Pt}-\mathrm{Pt}$ contribution, solid line) and fitted $\mathrm{Pt}-\mathrm{C}(\mathrm{O})_{\mathrm{L}}+\mathrm{Pt}-\mathrm{C}(\mathrm{O})_{\mathrm{S}}$ contributions $(\mathrm{dotted}$ line) of Pt/CNF500. Treatments are RED, VAC50, VAC100, VAC150, and VAC200, respectively.

very small metal particles present in the small size end of the particle size distribution curve. ${ }^{40}$

It is obvious that the presence of oxygen-containing groups leads to a stabilization of the Pt particles. The average particle size for $\mathrm{Pt} / \mathrm{CNF}$ is not only much smaller than for Pt/Vulcan $\mathrm{XC}-72$, but the $\mathrm{Pt}-\mathrm{Pt}$ first shell coordination numbers of 5.5 in Pt/CNF500 and 5.2 in Pt/CNF200 indicate that no sintering of the Pt particles occurs even after treatment at $500{ }^{\circ} \mathrm{C}$ in 

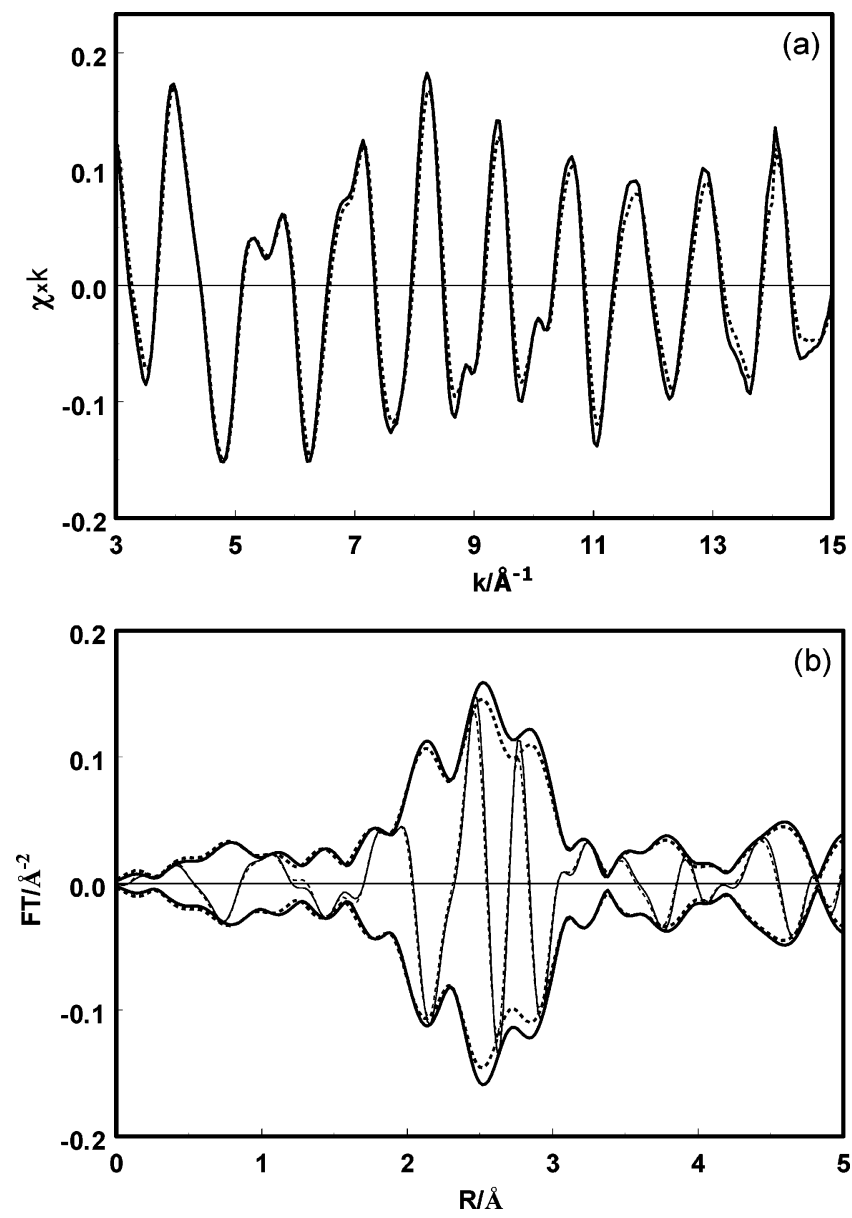

Figure 7. (part a) Experimental EXAFS data and (b) corresponding Fourier transforms ( $k^{1}$ weighted, $\left.\Delta k=3-14 \AA^{-1}\right)$ of Pt/Vulcan XC72 (solid line, REDRT; dotted line, VACRT).

TABLE 5: Fit Parameters of EXAFS Spectra ${ }^{a}$ and Variances for Model Spectra of Pt/Vulcan XC-72

\begin{tabular}{|c|c|c|c|c|c|c|c|}
\hline \multirow[b]{2}{*}{ treatment } & \multirow[b]{2}{*}{ scatter } & \multirow{2}{*}{$\begin{array}{c}N \\
( \pm 10 \%)\end{array}$} & \multirow{2}{*}{$\begin{array}{c}R \\
\left(\AA \AA^{\circ}\right. \\
\pm 0.02 \AA)\end{array}$} & \multirow{2}{*}{$\begin{array}{c}\Delta \sigma^{2} \\
\left(10^{-3} \AA^{2}\right. \\
\pm 5 \%)\end{array}$} & \multirow{2}{*}{$\begin{array}{c}\Delta E_{0} \\
(\mathrm{eV} \\
\pm 10 \%)\end{array}$} & \multicolumn{2}{|c|}{$\begin{array}{c}k^{1}-\text { variance } \\
(\%)\end{array}$} \\
\hline & & & & & & im. & abs. \\
\hline \multirow{4}{*}{$\overline{\text { REDRT }}$} & $\mathrm{Pt}$ & 8.4 & 2.76 & 1.1 & -1.6 & 0.34 & 0.09 \\
\hline & $\mathrm{C}$ & 2.3 & 2.62 & 7.0 & -0.2 & & \\
\hline & $\mathrm{C}$ & 2.3 & 3.62 & 9.0 & -7.9 & & \\
\hline & $\mathrm{Pt}$ & 5.0 & 3.90 & 1.7 & -5.6 & & \\
\hline \multirow{4}{*}{ VACRT } & $\mathrm{Pt}$ & 8.2 & 2.76 & 1.6 & -2.0 & 0.27 & 0.08 \\
\hline & $\mathrm{C}$ & 2.5 & 2.58 & 8.0 & 4.9 & & \\
\hline & $\mathrm{C}$ & 2.7 & 3.62 & 10.0 & -9.4 & & \\
\hline & $\mathrm{Pt}$ & 5.1 & 3.90 & 2.5 & -6.2 & & \\
\hline
\end{tabular}

nitrogen atmosphere. This has been demonstrated to be crucial for the application of the nanosized Pt metal particles for a reaction under severe catalytic conditions. ${ }^{41}$

4.2. $\mathbf{P t}-\mathbf{C}$ Contribution. After reduction, a long $\mathrm{Pt}-\mathrm{C}(\mathrm{O})_{\mathrm{L}}$ distance around $2.6 \AA$ is observed for both $\mathrm{Pt} / \mathrm{CNF}$ and $\mathrm{Pt} /$ Vulcan XC-72 catalysts. With increasing evacuation temperature, this long $\mathrm{Pt}-\mathrm{C}(\mathrm{O})_{\mathrm{L}}$ distance disappears for the $\mathrm{Pt}$ / CNF200 and Pt/CNF500 samples. It has to be noted that the response on the evacuation temperature is different for both samples: The long $\mathrm{Pt}-\mathrm{C}(\mathrm{O})_{\mathrm{L}}$ distance disappears at a lower evacuation temperature for Pt/CNF500 $\left(T_{\mathrm{VAC}}=100{ }^{\circ} \mathrm{C}\right)$ than for $\mathrm{Pt} / \mathrm{CNF} 200\left(T_{\mathrm{VAC}}=150{ }^{\circ} \mathrm{C}\right)$. For the Pt/Vulcan $\mathrm{XC}-72$ sample, it was not possible to follow the disappearance of the long $\mathrm{Pt}-\mathrm{C}(\mathrm{O})_{\mathrm{L}}$ distance, because evacuation at higher temperatures led to a severe sintering of the Pt particles, making the

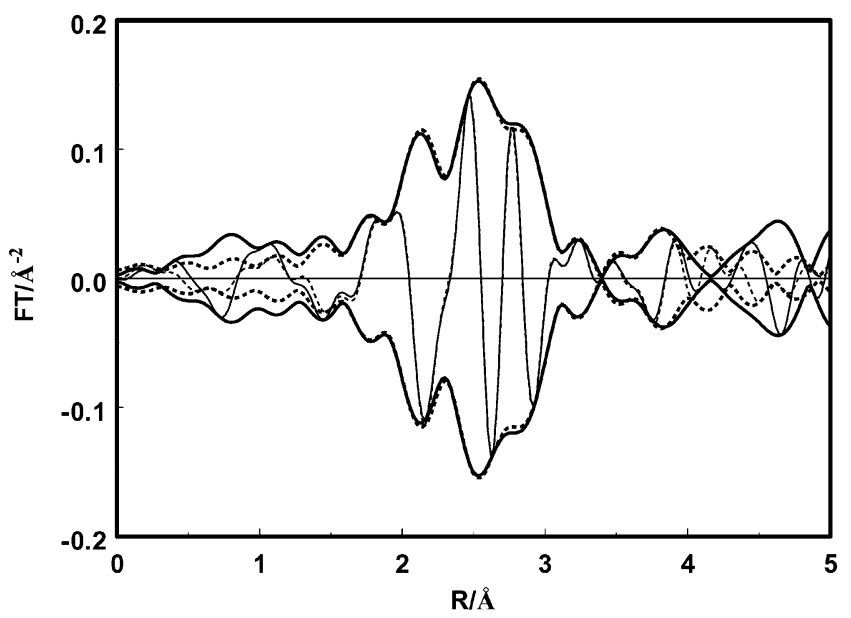

Figure 8. The Fourier transforms $\left(k^{1}\right.$ weighted, $\left.\Delta k=3.5-14 \AA^{-1}\right)$ of the experimental spectra (solid line) and total fit (dotted line) of REDRT.
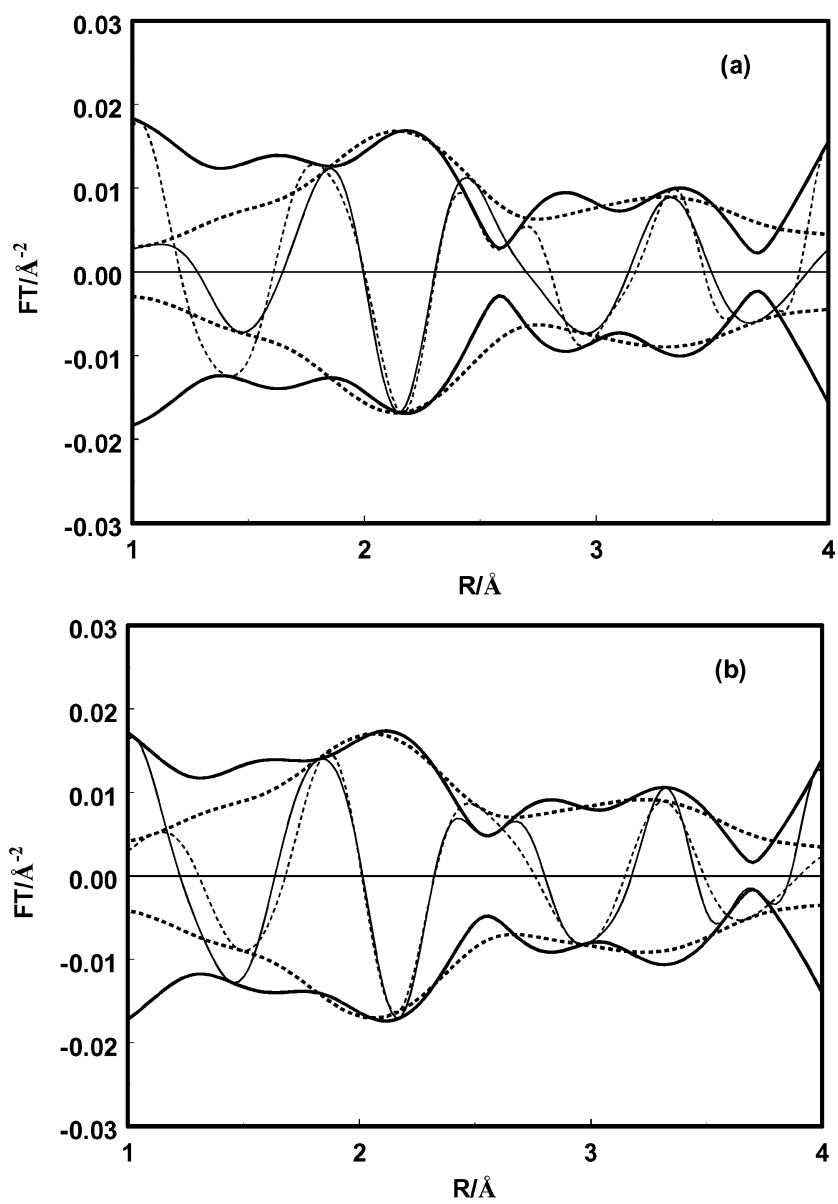

Figure 9. The Fourier transforms $\left(k^{1}\right.$ weighted, $\Delta k=3.5-9.5 \AA^{-1}$, $\mathrm{Pt}-\mathrm{C}$ phase corrected) of $\mathrm{Pt}-\mathrm{C}$ difference file (raw spectra minus fitted $\mathrm{Pt}-\mathrm{Pt}$ contributions, solid line) and fitted $\left(\mathrm{Pt}-\mathrm{C}_{1}\right)+\left(\mathrm{Pt}-\mathrm{C}_{2}\right)$ contributions (dotted line) of (part a) REDRT and (part b) VACRT.

detection of this distance impossible. However, after the evacuation of $\mathrm{Pt} / \mathrm{Vulcan} \mathrm{XC}-72$ at $\mathrm{RT}$, the long $\mathrm{Pt}-\mathrm{C}(\mathrm{O})_{\mathrm{L}}$ distance could still be detected, also implying that evacuation at high temperature is needed to remove this distance. After evacuation at higher temperatures, only a short $\mathrm{Pt}-\mathrm{C}(\mathrm{O})_{\mathrm{S}}$ distance is detected around $2.02 \AA$ with approximately the same total $\mathrm{Pt}-\mathrm{C}(\mathrm{O})$ coordination number.

As already mentioned in the Results section, it is almost impossible to distinguish with EXAFS between $\mathrm{C}$ and $\mathrm{O}$ as the backscatterer. However, the fact that the same kind of interaction 


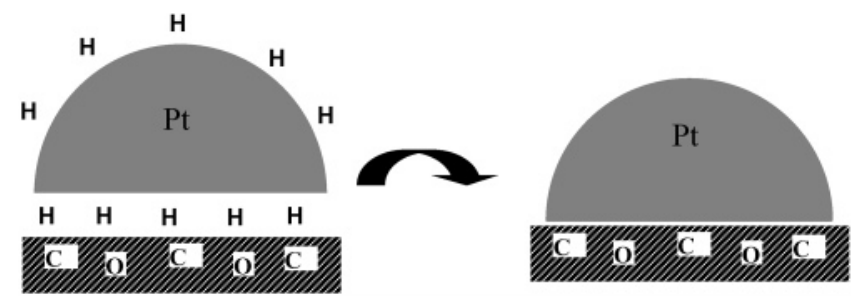

Figure 10. The schematic illustration of the changes in interfacial structure between the metal and the support induced by evacuation.

is detected in the metal-support interface of both types of carbon supports, combined with the information that no significant amount of oxygen-containing groups are present on the Vulcan XC-72 support, may lead to the conclusion that $\mathrm{C}$ is the neighboring atom in the metal-support interface.

The conventional view of the platinum-carbon support interface would suggest that the Pt atoms are in direct contact with the carbon support. If this would be the case under all experimental conditions, the $\mathrm{Pt}-\mathrm{C}$ bond distance would be a maximum of $2.09 \AA$ (atomic radius of Pt in Pt metal is $1.38 \AA$ and $\mathrm{C}$ in graphite is $0.71 \AA$ ). Only a similarly short distance is found experimentally after evacuation: $2.02 \AA$. After reduction, a $\mathrm{Pt}-\mathrm{C}$ distance is observed around $2.6 \AA$. If the value of the $\mathrm{Pt}$ radius is subtracted from the observed value after reduction, a difference of $1.22 \AA$ is obtained, which, in fact, is much closer to the bond distance in a $\mathrm{C}-\mathrm{H}$ bond $(1.1 \AA)$. The distance of $2.6 \AA$ detected after reduction is consistent with metal-support distances found in other precious metal catalysts having oxidic (macroporous flat and crystalline zeolitic) supports. As described in detail in the Introduction section, the metal-support distance for these systems shortens to about $2.1-2.2 \AA$ after evacuation at higher temperatures and reappears again after admission of hydrogen. A similar behavior is now observed for the $\mathrm{Pt}-\mathrm{C}$ coordination in this study. Therefore, we infer that the long metal-support distance is a general characteristic feature of interfaces consisting of hydrogen between interfacial metal atoms and support neighbors such as carbon atoms of carbon supports and oxygen anions of metal oxide supports, including zeolites. It is most logical to assume that close to each other multiple $\mathrm{Pt}-\mathrm{C}$ distances exist at the interface of $\mathrm{Pt}$ and carbon, all contributing to the XAFS signal, while various amounts of interfacial hydrogen is left upon evacuation at increasing temperatures. The changes in the interfacial structure between the metal and the CNF support caused by the existence of hydrogen in the interfacial area are schematically shown in Figure 10. From experience in hydrogenation catalysis at elevated pressure and temperature, it appears that $\mathrm{Pt} / \mathrm{CNF}$ catalysts are not prone to sintering at the prevailing conditions. ${ }^{13,30,31}$ Despite the long $\mathrm{Pt}-\mathrm{C} / \mathrm{O}$ distance, the metalsupport interaction is still significant and clearly prevents metal sintering. The precise nature of the $\mathrm{Pt}-\mathrm{H}-\mathrm{C} / \mathrm{O}$ interface is not fully known and deserves further experimental and theoretical work.

As already mentioned on Pt/Vulcan XC-72, hardly any difference in the $\mathrm{Pt}-\mathrm{C}$ contributions was found between REDRT and VACRT. However, after evacuation at RT, a small decrease in the $\mathrm{Pt}-\mathrm{Pt}$ coordination number, a small increase in the $\mathrm{Pt}-$ $\mathrm{Pt}$ Debye-Waller factor, and small increases in the $\mathrm{Pt}-\mathrm{C}$ coordination numbers of both carbon neighbor shells are observed. This can be explained by a slight morphology change of the Pt particles after desorption of hydrogen at RT. Flattening out of the Pt particles on the support surface can compensate the increase in Pt surface free energy because of the removal of chemisorbed hydrogen. This leads to (i) a lower amount of
Pt surface atoms, which are coordinatively unsaturated, and an increase of $\mathrm{Pt}$ atoms in contact with the carbon support, (ii) a decrease in the $\mathrm{Pt}-\mathrm{Pt}$ coordination number, and (iii) an increase in the $\mathrm{Pt}-\mathrm{Pt}$ Debye-Waller factor.

4.3. Detectability with EXAFS of Interfacial MetalSupport Contributions. The detection with EXAFS of support neighbors of metal atoms present in the metal-support interface is dependent on the metal particle size and morphology, the structure of the support surface plane, and the quality of the EXAFS experimental data. The interfacial metal coordination number as detected with EXAFS is fractional. The fraction of metal atoms present in the metal-support interface decreases with increasing metal particle size, finally leading to an undetectable contribution of the metal-support interface. For fcc noble metal particles dispersed on high surface area $\gamma-\mathrm{Al}_{2} \mathrm{O}_{3}$ supports with EXAFS noise levels of 0.001, the EXAFS signal arising from the metal-support interface becomes undetectable for particles with metal-metal coordination numbers larger than 8.5-9. The $\mathrm{Pt}-\mathrm{Pt}$ and $\mathrm{Pt}-\mathrm{O}_{\mathrm{L}}$ coordination number found for $\mathrm{Pt} / \gamma-\mathrm{Al}_{2} \mathrm{O}_{3}$ catalysts after reduction at $300{ }^{\circ} \mathrm{C}$ is 4.8 and 1.2 , respectively. ${ }^{28}$ The (fractional) EXAFS $\mathrm{Pt}-\mathrm{O}_{\mathrm{L}}$ coordination of 1.2 translates to a real $\mathrm{Pt}-\mathrm{O}_{\mathrm{L}}$ coordination number of 3 , implying that $\mathrm{Pt}$ in the metal-support interface is 3-fold coordinated by oxygen atoms of the support. However, in this study for the Pt/CNF samples with a slightly higher average $\mathrm{Pt}-\mathrm{Pt}$ coordination around 5.5, the (fractional) $\mathrm{Pt}-\mathrm{O}_{\mathrm{L}}$ coordination number is in the range 1.6-2.0, whereas for the much larger $\mathrm{Pt}$ particles on Vulcan XC-72 (Pt-Pt around 8.5), an even higher (fractional) $\mathrm{Pt}-\mathrm{C}_{\mathrm{L}}$ coordination number around 2.5 is detected. This can only be explained by a different structure of the metalsupport interface for both types of carbon-supported Pt particles leading to a larger number of neighboring carbon atoms. This increases the detectability of the contribution of the metalsupport interface for larger Pt metal particles.

4.4. Structure of the Metal-Support Interface in $\mathrm{Pt} / \mathrm{CNF}$ and Pt/Vulcan XC-72. The structure of layered graphite gives basically two kinds of surfaces: prismatic (edge) surfaces and basal plane surfaces. The structure of the metal-support interface on carbon-supported metal particles depends on the morphology of the surface on which the metal atoms are anchored. By assuming a half-spherical shape of the platinum particles sticking with a particular fcc orientation, it is possible to derive an expression for the fraction $(f)$ of the number of interfacial platinum atoms: $f=4 R / d$, with $R$ the atomic radius of $\mathrm{Pt}$ and $d$ the diameter of the platinum particle. ${ }^{23}$ The fraction is calculated to be 0.35 , using $d=16 \AA$ with $R=1.38 \AA$ on $\mathrm{Pt} /$ Vulcan-XC72, while it is 0.55, using $d=10 \AA$ with $R=$ $1.38 \AA$ on Pt/CNF200.

By using the EXAFS $\mathrm{Pt}-\mathrm{C}_{\mathrm{L}}$ coordination number of 2.3 (REDRT) for both the first and second carbon shell at 2.62 and $3.62 \AA$, respectively, a real interfacial coordination number around 6.6 can be calculated for both coordination shells. A model with six nearest and six second nearest $\mathrm{Pt}-\mathrm{C}_{\mathrm{L}}$ neighbors is possible for the Pt growing epitaxially on the basal (0001) plane of carbon as shown in Figure 11. The $\mathrm{C}-\mathrm{C}$ distance of $1.415 \AA$ is very close to the $\mathrm{Pt}-\mathrm{Pt}$ radius of $1.38 \AA$, making an epitaxial interface not unlikely. Using this assumption, we find that the structure of the metal-support interface can be further analyzed. With the experimental value of $2.62 \AA$ for the $\mathrm{Pt}-$ $\mathrm{C}_{\mathrm{L}}$ first shell distance and the $\mathrm{C}-\mathrm{C}$ bond distance from graphite $1.415 \AA$, it can be calculated that the Pt atom sits $2.205 \AA$ above the center of the basal plane. Calculating now the distance to the second carbon neighbor, we obtain a value of $3.59 \AA$, which is $0.03 \AA$ lower than the observed distance of $3.62 \AA$. For 
Top view
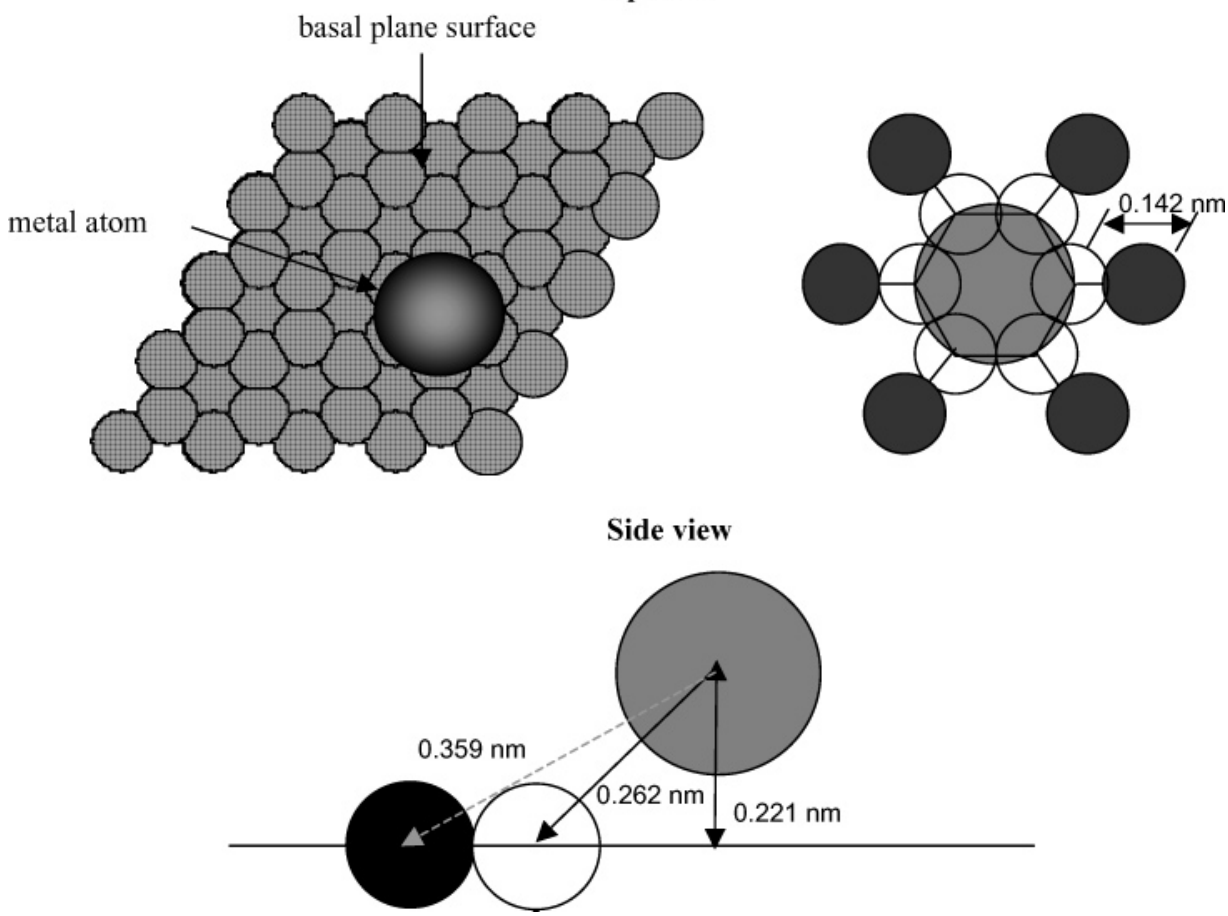

Figure 11. Structural model of Pt supported on Vulcan XC-72; hollow $(\mathrm{O})$ and solid circles $(O)$ refer to the first and second carbon shell, respectively.

EXAFS studies, the limits of accuracy in the bond distance can be normally calculated to be $\pm 0.01 \AA$, ${ }^{36}$ showing that the calculated value is close to the experimental value. This indicates that the EXAFS coordination parameters are in agreement with the proposed model for the structure of the metal-support interface. The results obtained in an earlier EXAFS study of our group ${ }^{42}$ on the formation of the metal-support interface by controlled heating of the precursor $\left[\mathrm{Pt}\left(\mathrm{NH}_{3}\right)_{4}\right](\mathrm{OH})_{2}$ impregnated on $\gamma-\mathrm{Al}_{2} \mathrm{O}_{3}$ in flowing hydrogen fully support the findings in this study. The EXAFS data obtained after reduction at 180 ${ }^{\circ} \mathrm{C}$ are consistent with a structural model in which small $\mathrm{Pt}$ particles grow with a (111) epitaxy on the (111) surface plane of the high surface area $\gamma-\mathrm{Al}_{2} \mathrm{O}_{3}$ support. Also, in this case, two metal-support oxygen distances have been detected at 2.70 and $3.84 \AA$ A. Just like for the Pt carbon interface as studied here, the second shell interfacial distance is a consequence of the existence of a first shell interfacial distance at $2.70 \AA$, caused by the presence of hydrogen in the interface between the $\mathrm{Pt}$ metal particle and the support. Using the (111) epitaxial model, we can calculate a second shell $\mathrm{Pt}-\mathrm{O}$ distance of $3.86 \AA$, which is almost equal to the value found in the EXAFS analysis.

Compared with Vulcan-XC72, the carbon nanofibers used in this study have very different physicochemical properties (i.e., a fishbone structure, higher surface area, and higher purity). According to the already-calculated fraction of Pt atoms in the metal-support interface for the Pt/CNF samples, one interfacial $\mathrm{Pt}$ atom would only feel about four carbon atoms. This suggests that Pt particles are not located on the basal (0001) support surface, which is highly symmetrically ordered and will give more carbon neighbors. Also, it is not likely that the metal particles are intercalated between two graphite layers, because the particle size around $10 \AA$ is much larger than the graphite layer distance of $3.4 \AA$. Because the introduction of the oxygencontaining groups seems to be essential for the synthesis of much smaller Pt particles than on Vulcan, the possible adsorption sites of oxygen-containing groups on the CNF surface can give some hints about the interfacial structure between the Pt particles and the CNF support. ${ }^{43}$ To investigate the interaction of atomic oxygen with graphite surfaces, using first-principles total energy calculations, Incze et al. ${ }^{44}$ proposed that a zigzag edge surface of carbon graphite is the most reactive one, followed by armchair and basal plane surfaces. Oxygen atoms absorbed on the sites of a zigzag surface are more stable. It is also well-known that the chemistry and morphology of the prismatic surfaces of graphite play a major role for the graphite anode performance in lithium ion cells (e.g., in chemical and electrochemical reactivity, interaction with the solid electrolyte interphase SEI, etc.). ${ }^{45}$ By placing the Pt particles on the zigzag or armchair surfaces, the interfacial Pt atoms would have only four carbon neighbors (see Figure 12). This is in excellent agreement with the EXAFS results. This would also lead to an explanation of the role which the oxygen-containing groups play in stabilizing the Pt particles on the CNF support. More research is needed to fully explain the mechanism of this stabilizing process.

4.5. Influence of Particle Size, Hydrogen Chemisorption, and Carbon Support Properties on the Electronic Structure of the Supported Pt Particles. In going from bulk to very small metal particles, the electronic structure of the metal atoms is changing because of the dehybridization of the spd metal orbitals. ${ }^{46}$ The dehybridization results in increased electron density (less delocalization) between the atoms in the small particle, which in turn results in a contraction of the interatomic distance. At the same time, caused by the loss of neighboring atoms, the phonon spectrum softens, causing a broader potential well. This, in turn, leads to a larger disorder. The Pt structural parameters obtained by the EXAFS analysis after evacuation are fully consistent with the theoretical and experimental results presented in the literature. ${ }^{46}$ The first shell $\mathrm{Pt}-\mathrm{Pt}$ coordination as obtained for the large Pt particles supported on Vulcan-XC72 (VACRT) has a distance close to the $\mathrm{Pt}-\mathrm{Pt}$ distance in bulk $\mathrm{Pt}$ (2.76 vs $2.77 \AA$ ) with a slightly larger Debye-Waller factor $\left(0.0016 \AA^{-1}\right)$. The much smaller Pt particles supported on CNF (VAC200) show a considerable contraction (Pt/CNF200, 2.69 $\AA$; Pt/CNF500, $2.68 \AA$ ) with a considerable increase in the Debye-Waller factor (Pt/CNF200, $0.0066 \AA^{-1}$; Pt/CNF500, $0.0071 \AA^{-1}$ ). 


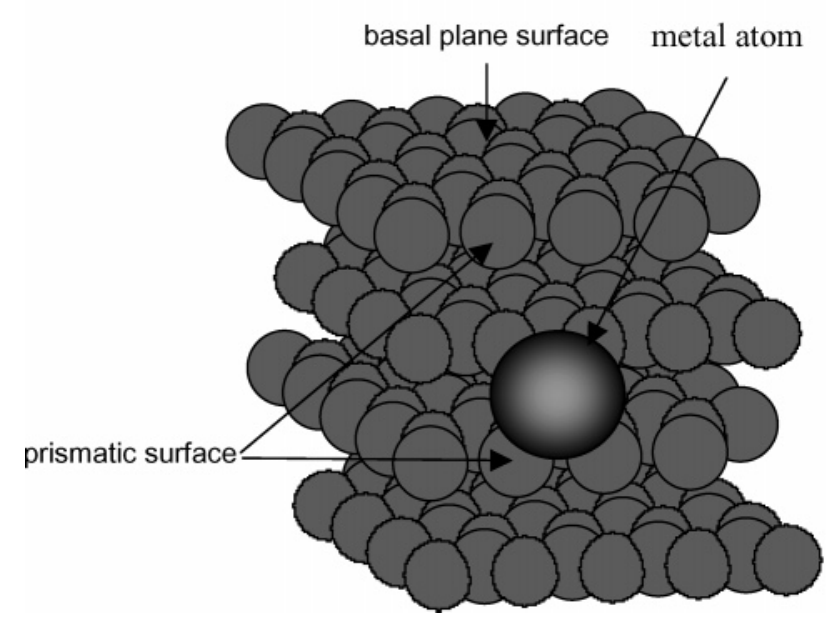

\section{Top view}

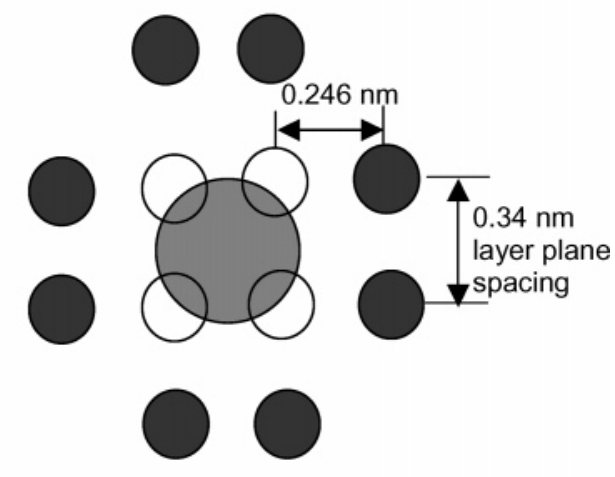

Figure 12. Structural model of Pt supported on CNF.

Hydrogen chemisorption is showing the reverse effect by going from large to small Pt particles. This can be explained by the fact that hydrogen chemisorption leads to an increase in the amount of neighboring atoms for the surface Pt. Hydrogen is now sharing $\mathrm{Pt}$ valence electron density in the $\mathrm{Pt}-\mathrm{H}$ bond, ${ }^{20,22}$ making the neighboring $\mathrm{Pt}-\mathrm{Pt}$ bonds weaker. In EXAFS, this effect is averaged over the whole particle, effectively leading to an observed larger $\mathrm{Pt}-\mathrm{Pt}$ distance. The first shell $\mathrm{Pt}-\mathrm{Pt}$ coordination in Pt/Vulcan-XC72 after hydrogen chemisorption (REDRT) is not affected by hydrogen chemisorption $(2.76 \AA)$; however, a small decrease in disorder is observed (0.0011 vs $0.0016 \AA^{2}$ ). The effects are much larger for the smaller $\mathrm{Pt}$ particles supported on CNF. Upon hydrogen chemisorption, the $\mathrm{Pt}-\mathrm{Pt}$ distance relaxes back close to the value of $\mathrm{Pt}$ foil $(\mathrm{Pt} /$ CNF200, 2.77 vs $2.69 \AA$; Pt/CNF500, 2.76 vs $2.68 \AA$ ) with also a significant decrease in disorder (Pt/CNF200, $0.0011 \mathrm{vs}$ $0.0066 \AA^{2}$; Pt/CNF500, 0.0016 vs $\left.0.0071 \AA^{2}\right)$. These results are in complete agreement with previous reports for $\mathrm{Pt} / \gamma-\mathrm{Al}_{2} \mathrm{O}_{3}{ }^{47}$ and $\mathrm{Ir} / \gamma-\mathrm{Al}_{2} \mathrm{O}_{3}{ }^{26}$

The third important factor which can influence the electronic structure of the metal particles are the properties of the support. The influence of the electron richness (depending on the acid/ base properties) of the support oxygen atoms of oxidic (macroporous flat and zeolitic) supports on the catalytic and electronic properties of the supported metal particles has been extensively studied. ${ }^{20-22}$ Preliminary catalytic experiments on the Pt/CNF samples show an increase in activity for Pt-catalyzed $\mathrm{C}=\mathrm{C}$ double bond hydrogenation (cyclohexene and toluene hydrogenation) for CNF supports with increasing amounts of oxygen-containing groups. The same trend is observed for $\mathrm{Pt}$ particles supported on oxidic supports, which have a low electron richness (acidic) on the support oxygen atoms. Therefore, the CNF200 support can be considered to be more acidic than the CNF500. In this model, the oxygen-containing groups in the CNF support withdraw electron density from the carbon atoms, resulting in a lower electron richness of the support carbon atoms. In analogy with oxidic supports, this may affect the catalytic and electronic properties of the Pt particles. However, the already-mentioned catalytic effects are small for the CNF-supported samples. Larger effects are observed for oxide-supported Pt particles, where the differences in electron richness of the support oxygen atoms are larger. Moreover, it has to be mentioned that a reverse support effect is found for the hydrogenation of reactants having $\mathrm{C}=\mathrm{O}$ double bonds. The activity for hydrogenation of cinnemaldehyde to cinnamyl alcohol is higher for Pt and Ru supported on CNF with low amounts of oxygen-containing groups, ${ }^{13,30}$ whereas the same activity trends are observed for the hydrogenation of benzaldehyde to benzyl alcohol ${ }^{48,49}$ using Pt or Pd particles supported on oxides with a high electron richness (more basic) of the support oxygen atoms.

Indications that the oxygen-containing groups in the $\mathrm{CNF}$ support influence the electronic structure of $\mathrm{Pt}$ can be found in Figure 5. In Figure 5a,b, the $\mathrm{Pt}-\mathrm{Pt}$ bond distance and the Debye-Waller factor are plotted as a function of the evacuation treatment carried out at different temperatures. All data were measured at liquid nitrogen temperature. As a comparison, the same kind of data are also shown for acidic $\mathrm{Pt} / \mathrm{Cl}-\mathrm{Al}_{2} \mathrm{O}_{3}$ and basic $\mathrm{Pt} / \mathrm{K}-\mathrm{Al}_{2} \mathrm{O}_{3}$ catalysts. ${ }^{50}$ When increasing the evacuation temperature, a decrease in $\mathrm{Pt}-\mathrm{Pt}$ bond distance is observed with the effect highest for the basic oxidic support. An increase in the Debye-Waller factor is found also with the largest effect for the basic oxidic support. It can be seen in Figure 5 that the same trends are observed for the CNF samples (effect largest for the Pt/CNF500 sample); however, the effect of the oxygen groups in the CNF supports are smaller. It has been proven elsewhere $^{21}$ that the nature of the metal-support interaction involves a charge rearrangement from the $\mathrm{Pt}$ atoms in the metal-support interface to the center of the Pt cluster when the support oxygen atoms have a higher electron richness (more basic). This results in an opposite trend as induced by chemisorption of hydrogen: A smaller equilibrium $\mathrm{Pt}-\mathrm{Pt}$ distance and a broadened potential well, resulting in a larger structural disorder. This explains the different response on evacuation for the $\mathrm{Pt} / \mathrm{Cl}-\mathrm{Al}_{2} \mathrm{O}_{3}$ and $\mathrm{Pt} / \mathrm{K}-\mathrm{Al}_{2} \mathrm{O}_{3}$ samples and may indicate that oxygen-containing groups in $\mathrm{CNF}$ supports also influence the electronic properties of supported Pt particles. More research is needed to further verify the effect of the oxygen-containing groups of the CNF support on the catalytic and electronic properties of the Pt particles.

\section{Conclusion}

Very small Pt particles with diameters around $1 \mathrm{~nm}$ have been prepared on CNF supports, which have controllable amounts of oxygen-containing groups. The $\mathrm{Pt}$ particles have high thermostability. In contrast, much larger Pt particles with sizes around $1.6 \mathrm{~nm}$ have been detected for Pt/Vulcan XC-72, a commercial fuel cell electrode. After reduction and in the presence of hydrogen, a long $\mathrm{Pt}-\mathrm{C}$ distance around $2.6 \AA$ is observed in the interface between the Pt particles and the carbon support. Upon evacuation at higher temperatures on $\mathrm{Pt} / \mathrm{CNF}$, 
the long distance $\mathrm{Pt}-\mathrm{C}$ contribution decreased and eventually disappeared. A much shorter distance at about $2.02 \AA$ can be observed in a vacuum. Because the same kind of behavior has been observed in the literature for Pt particles supported on high surface area oxides, the origin of the long $\mathrm{Pt}-\mathrm{C}$ distance has been attributed to the presence of hydrogen in the interface between metal and support atoms.

A higher $\mathrm{Pt}-\mathrm{C}$ coordination number was detected in the metal-support interface of Pt/Vulcan XC-72. A structural model is presented in which the metal cluster interacts with the carbonrich surface of the basal (0001) plane of carbon graphite. However, on CNF-supported Pt samples, only about four carbon neighbors were detected per interfacial Pt atom. In this case, an interface with a zigzag or armchair edge surface is in agreement with the EXAFS coordination parameters. It has been argued that modification of the carbon surface with oxygen groups is crucial for the deposition of small metal particles.

The EXAFS data analysis shows a marked contraction of the $\mathrm{Pt}-\mathrm{Pt}$ coordination distance and an increase in the DebyeWaller factor during evacuation at different temperatures for the $\mathrm{Pt} / \mathrm{CNF}$ samples. The response on the evacuation treatment of the Pt/CNF200 and Pt/CNF500 samples is compared with that of a $\mathrm{Pt} / \mathrm{Cl}-\mathrm{Al}_{2} \mathrm{O}_{3}$ and $\mathrm{Pt} / \mathrm{K}-\mathrm{Al}_{2} \mathrm{O}_{3}$ catalyst, respectively. A model has been discussed in which the oxygen-containing groups of the CNF support can have an influence on the electronic properties of the supported Pt particles.

Acknowledgment. The authors thank C. van der Spek for performing the TEM measurements. The synchrotron laboratories of HASYLAB (Hamburg, Germany) and NSLS (Brookhaven) are acknowledged for the allocated beamtime. This research project is supported by the Council for Chemical Sciences of The Netherlands Organization for Scientific Research with financial aid from The Netherlands Technology Foundation (CW/STW 349-5357).

\section{References and Notes}

(1) Amine, K.; Yasuda, K.; Takenaka, H. Ann. Chim. (Paris) 1998, 23,331 .

(2) Pattabiraman, R. Appl. Catal., A 1997, 153, 9.

(3) Torre, T.; Aricò, A. S.; Alderucci, V.; Antonucci, V.; Giordano, N. Appl. Catal., A 1994, 114, 257.

(4) Raróg-Pilecka, W.; Szmigiel, D.; Kowalczyk, Z.; Jodzis, S.; Zielinski, J. J. Catal. 2003, 218, 465.

(5) Pérez-Cadenas, A. F.; Moreno-Castilla, C.; Maldonado-Hódar, F. J.; Fierro, J. L. G. J. Catal. 2003, 217, 30.

(6) Bessel, C. A.; Laubernds, K.; Rodriguez, N. M.; Baker, R. T. K. J. Phys. Chem. B 2001, 105, 1115.

(7) Pham-Huu, C.; Keller, N.; Charbonniere, L. J.; Ziessel, R.; Ledoux, M. J. Chem. Commun. 2000, 1871.

(8) Baker, R. T. K.; Laubernds, K.; Wootsch, A.; Paál, Z. J. Catal. 2000, 193, 165.

(9) Mitchell, P. C. H.; Ramirez-Cuesta, A. J.; Parker, S. F.; Tomkinson, J. J. Mol. Struct. 2003, 651-653, 781.

(10) de Jong, K. P.; Geus, J. W. Catal. Rev.-Sci. Eng. 2000, 42, 481. (11) Serp, P.; Corrias, M.; Kalck, P. Appl. Catal., A 2003, 253, 337.

(12) Mojet, B. L.; Hoogenraad, M. S.; van Dillen, A. J.; Geus, J. W.; Koningsberger, D. C. J. Chem. Soc., Faraday Trans. 1997, 93, 4371.

(13) Toebes, M. L.; Prinsloo, F. F.; Bitter, J. H.; van Dillen, A. J.; de Jong, K. P. J. Catal. 2003, 214, 78.
(14) Coloma, F.; Sepúlveda-Escribano, A.; Rodríguez-Reinoso, F. Appl. Catal., A 1995. 123, L1.

(15) Bachiller-Baeza, B.; Guerrero-Ruiz, A.; Rodríguez-Ramos, I. Appl. Catal., A 2000, 192, 289.

(16) Yacaman, M. J.; Dominguez, E.; Manuel, J. J. Catal. 1980, 64, 213.

(17) Bett, J.; Kinoshita, K.; Routsis, K.; Stonehart, P. J. Catal. 1973, 29,160 .

(18) Lampitt, R. A.; Carrette, L. P. L.; Hogarth, M. P.; Russell, A. E. J. Electroanal. Chem. 1999, 460, 80.

(19) Maniguet, S.; Matthew, R. J.; Russell, A. E. J. Phys. Chem. B 2000, 104, 1998.

(20) Mojet, B. L.; Miller, J. T.; Ramaker, D. E.; Koningsberger, D. C. J. Catal. 1999, 186, 373.

(21) Ramaker, D. E.; de Graaf, J.; van Veen, J. A. R.; Koningsberger, D. C. J. Catal. 2001, 203, 7.

(22) Koningsberger, D. C.; Oudenhuijzen, M. K.; de Graaf, J.; van Bokhoven, J. A.; Ramaker, D. E. J. Catal. 2003, 216, 178.

(23) Van Zon, J. D.; Koningsberger, D. C.; van Blik, H. J.; Sayers, D. E. J. Chem. Phys. 1985, 82, 5742 .

(24) Martens, H. A.; Prins, R.; Zandbergen, H.; Koningsberger, D. C. J. Phys. Chem. 1988, 92, 1903.

(25) van Zon, F. B. M.; Maloney, S. D.; Gates, B. C.; Koningsberger, D. C. J. Phys. Chem. 1993, 115, 10317.

(26) Koningsberger, D. C.; van Zon, F. B. M.; Vaarkamp, M.; MuñozPaez, A. X-ray Absorption Fine Structure for Catalysts and Surfaces; Iwasawa, Y., Ed.; Tokyo, 1995; p 257.

(27) Vaarkamp, M.; Modica, F. S.; Miller, J. T.; Koningsberger, D. C. J. Catal. 1993, 144, 611 .

(28) Vaarkamp, M.; Miller, J. T.; Modica, F. S.; Koningsberger, D. C. J. Catal. 1996, 163, 294.

(29) de Graaf, J.; van Dillen, A. J.; de Jong, K. P.; Koningsberger, D. C. J. Catal. 2001, 203, 307.

(30) Toebes, M. L.; Zhang, Y.; Hájek, J.; Bitter, J. H.; van Dillen, A. J.; Murzin, D. Y.; Koningsberger, D. C.; de Jong, K. P. J. Catal. 2004 226, 215.

(31) Toebes, M. L.; Nijhuis, T. A.; Hájek, J.; Bitter, J. H.; van Dillen,

A. J.; Murzin, D. Y.; de Jong, K. P. Submitted for publication.

(32) Toebes, M. L.; Bitter, J. H.; van Dillen, A. J.; de Jong, K. P. Catal. Today 2002, 76, 33.

(33) Toebes, M. L.; van Heeswijk, J. M. P.; Bitter, J. H.; van Dillen, A. J.; de Jong, K. P. Carbon 2004, 42, 307.

(34) Vaarkamp, M.; Mojet, B. L.; Modica, F. S.; Miller, J. T.; Koningsberger, D. C. J. Phys. Chem. 1995, 99, 16067.

(35) Vaarkamp, M.; Linders, J. C.; Koningsberger, D. C. Physica B 1995 208/209, 159

(36) Koningsberger, D. C.; Mojet, B. L.; van Dorssen, G. E.; Ramaker, D. E. Top. Catal. 2000, 10, 143.

(37) Ros, T. G.; Keller, D. E.; van Dillen, A. J.; Geus, J. W.; Koningsberger, D. C. J. Catal. 2002, $211,85$.

(38) Pandya, K. I.; Koningsberger, D. C. Physica B 1989, 158, 386.

(39) Koningsberger, D. C.; Vaarkamp, M. Physica B 1995, 209, 633.

(40) de Graaf, J. Ph.D. Thesis, Utrecht University, Utrecht, The Netherlands, 2001.

(41) Joo, S. H.; Choi, S. J.; Oh, I.; Kwak, J.; Terasaki, O.; Ryoo, R. Nature 2001, 412, 169

(42) Muñoz-Paez, A.; Koningsberger, D. C. J. Phys. Chem. 1995, 99 4193.

(43) Ros, T. G. Ph.D. Thesis, Utrecht University, Utrecht, The Netherlands, 2002

(44) Incze, A.; Pasturel, A.; Chatillon, C. Surf. Sci. 2003, 537, 55.

(45) Winter, M.; Novak, P.; Monnier, A. J. Electrochem. Soc. 1998 $145,428$.

(46) Delley, B.; Ellis, D. E.; Freeman, A. J.; Baerends, E. J.; Post, D. Phys. Rev. B 1983, 27, 2132.

(47) Oudenhuijzen, M. K.; Bitter, J. H.; Koningsberger, D. C. J. Phys. Chem. B 2001, 105, 4616.

(48) Vannice, M. A.; Poondi, D. J. Catal. 1997, 169, 166

(49) Vannice, M. A.; Poondi, D. J. Catal. 1998, 178, 386.

(50) Oudenhuijzen, M. K. Ph.D. Thesis, Utrecht University, Utrecht, The Netherlands, 2002. 